\title{
Complement C3a and C5a receptors promote GVHD by suppressing mitophagy in recipient dendritic cells
}

Hung Nguyen, ${ }^{1}$ Sandeepkumar Kuril, ${ }^{2}$ David Bastian, ${ }^{1}$ Jisun Kim, ${ }^{3}$ Mengmeng Zhang, ${ }^{1}$

Silvia G. Vaena, ${ }^{3}$ Mohammed Dany, ${ }^{3}$ Min Dai, ${ }^{4}$ Jessica Lauren Heinrichs, ${ }^{5}$

Anusara Daenthanasanmak, ${ }^{1}$ Supinya lamsawat, ${ }^{1}$ Steven Schutt, ${ }^{1}$ lianing Fu, ${ }^{6}$ Yongxia $\mathrm{Wu},{ }^{1}$ David P. Fairlie, ${ }^{7}$ Carl Atkinson, ${ }^{1,8}$ Besim Ogretmen, ${ }^{3}$ Stephen Tomlinson, ${ }^{1,9}$ and Xue-Zhong $\mathbf{Y u}^{1,10}$

'Department of Microbiology and Immunology and 'Division of Pediatric Hematology/Oncology, Medical University of South Carolina, Charleston, South Carolina, USA. ${ }^{3}$ Department of Biochemistry and Molecular Biology and ${ }^{4}$ Department of Hematology, Nanfang Hospital, Southern Medical University, Guangzhou, China. ${ }^{5}$ Department of Surgery, Feinberg School of Medicine, Northwestern University, Chicago, Illinois, USA. ${ }^{6}$ Columbia Center for Translational Immunology, Columbia University, New York City, New York, USA. ${ }^{7}$ Australian Research Council Centre of Excellence in Advanced Molecular Imaging, Institute for Molecular Bioscience, The University of Queensland, Brisbane, Queensland, Australia. ${ }^{8}$ Department of Surgery, Transplant Immunobiology Laboratory, ${ }^{9}$ Research Service, Ralph H. Johnson Veterans Affairs Medical Center, and ${ }^{10}$ Department of Medicine, Medical University of South Carolina, Charleston, South Carolina, USA.

Graft-versus-host disease (CVHD) is a major complication of allogeneic hematopoietic cell transplantation (HCT). DCs play critical roles in CVHD induction. Modulating autophagy represents a promising therapeutic strategy for the treatment of immunological diseases. Complement receptors C3aR/C5aR expressed on DCs regulate immune responses by translating extracellular signals into intracellular activity. In the current study, we found that C3aR/C5aR deficiency enhanced ceramidedependent lethal mitophagy (CDLM) in DCs. Cotransfer of host-type $\mathrm{C}^{\mathrm{a}} \mathrm{aR} \mathrm{R}^{-/-} / \mathrm{C5}_{\mathrm{aR}} \mathrm{R}^{-/-} \mathrm{DCs}$ in the recipients significantly improved CVHD outcome after allogeneic $\mathrm{HCT}$, primarily through enhancing CDLM in DCs. C3aR/C5aR deficiency in the host hematopoietic compartment significantly reduced CVHD severity via impairing Th1 differentiation and donor T cell glycolytic activity while enhancing Treg generation. Prophylactic treatment with $\mathrm{C} 3 \mathrm{aR} / \mathrm{C5} \mathrm{aR}$ antagonists effectively alleviated CVHD while maintaining the graft-versus-leukemia (GVL) effect. Altogether, we demonstrate that inhibiting $\mathrm{C} 3 \mathrm{aR} / \mathrm{C5} \mathrm{aR}$ induces lethal mitophagy in DCs, which represents a potential therapeutic approach to control CVHD while preserving the GVL effect.

Conflict of interest: The authors have declared that no conflict of interest exists.

License: Copyright 2018, American Society for Clinical Investigation.

Submitted: April 17, 2018

Accepted: November 14, 2018

Published: December 20, 2018

Reference information: JCI Insight. 2018;3(24):e121697. https://doi.org/10.1172/jici. insight.121697.

\section{Introduction}

The development of graft-versus-host disease (GVHD) limits the success of hematopoietic cell transplantation (HCT) (1). Priming and subsequent activation of donor T cells by host antigen-presenting cells (APCs) precede the development of GVHD. Among APCs, DCs are the most potent and are capable of inducing GVHD (2).

Autophagy is an intracellular degradation process yielding cytosolic components (3). Autophagy has been suggested to be inversely correlated with cell growth (4). Autophagy is required for maintaining tolerance after HCT via augmenting survival and function of Tregs (5). Deficiency of autophagy in host DCs accelerates GVHD severity (6). Paradoxically, excessive levels of autophagy in DCs impaired their migration and antigen-presenting capacity (7). DCs treated with the potent autophagy inducer rapamycin (RAPA) exhibited decreased expression of MHCII and costimulatory molecules (8). RAPA-treated DCs enhance the apoptosis of alloreactive CD4 T cells, which had a reduced capacity to induce GVHD in vivo (8). Together, these findings suggest that promoting autophagy in DCs is an attractive strategy for treating GVHD. Mitophagy is a cellular process for the degradation of mitochondria by autophagic machinery (9). Mitophagy can promote cell survival during starvation or it can progress to cell death (lethal mitophagy) (10). Ceramide mediates mitophagy, which results in cell death in various human cancer cells (11). However, the mechanism by which mitophagy regulates DC fate after HCT is inconclusive. 
The generation of central complement proteins $\mathrm{C} 3$ and $\mathrm{C} 5$ during complement activation is implicated in the pathogenesis of GVHD (12-14). These proteins are cleaved at the cell membrane to produce effector molecules, including the complement anaphylatoxins (ATs) C3a and C5a. The ATs exert their biological functions through binding to their cognate $G$ protein-coupled receptors C3aR and C5aR. ATs modify T cell activation and differentiation through direct signaling on $\mathrm{T}$ cells. Expression of $\mathrm{C} 3 \mathrm{aR}$ and $\mathrm{C} 5 \mathrm{aR}$ on donor T cells is essential for GVHD development after HCT (15). During cognate interactions, APCs produce ATs and upregulate the expression of $\mathrm{C} 3 \mathrm{aR}$ and $\mathrm{C} 5 \mathrm{aR}$ on their surface (16). ATs thus have an effect on APC activation and maturation in an autocrine manner (15). In APCs, C3aR/C5aR ligation induces upregulation of costimulatory molecules, CD80 and CD86, while also elevating the release of proinflammatory cytokines, such as IL-12 and IL-23 (16). Meanwhile, C3aR/C5aR-mediated signals induce secretion of IFN- $\gamma$ and IL-2 from T cells. Therefore, signaling initiated by C3aR/C5aR on APCs drives Th1/Th17 differentiation (17) and suppresses Treg generation (18). While Th1 and Th17 promote GVHD pathology while Tregs suppress GVHD (19) and recipient APCs are critical for GVHD initiation (20), the roles of C3aR/C5aR in GVHD pathobiology are unclear.

$\mathrm{C} 3 \mathrm{aR} / \mathrm{C} 5 \mathrm{aR}$ activation has been reported to lead to Akt signaling (21), which suppresses mTORindependent autophagy in $\mathrm{CD}^{+} \mathrm{T}$ cells $(22,23)$. Genetic or pharmacologic inhibition of $\mathrm{C} 3 \mathrm{aR} / \mathrm{C} 5 \mathrm{aR}$ may promote autophagy (24), but how C3aR/C5aR-triggered DC autophagy affects GVHD and graftversus-leukemia (GVL) responses after HCT is unknown.

We demonstrate here that $\mathrm{C} 3 \mathrm{aR} / \mathrm{C} 5 \mathrm{aR}$ signaling suppressed lethal mitophagy in DCs after HCT. Blockade of $\mathrm{C} 3 \mathrm{aR} / \mathrm{C} 5 \mathrm{aR}$ activation significantly enhanced mitophagy in recipient DCs, which correlated with improved GVHD outcomes after HCT. Complement C3aR/C5aR signaling was required for optimal GVL activity, but prophylactic treatment with C3aR/C5aR antagonists effectively separated GVH and GVL responses after HCT. Hence, our study provides fundamental insights into the regulation of autophagy by complement signaling and validates targeting complement signaling as what we believe to be a novel therapeutic approach to control GVHD and tumor relapse.

\section{Results}

Regulation of survival and activation of recipient DCs by C3aR/C5aR signaling through attenuating mitophagy activity. While $\mathrm{C} 3 \mathrm{aR} / \mathrm{C} 5 \mathrm{aR}$ signaling is required for donor $\mathrm{T}$ cell activation, metabolism, and GVHD-inducing capacity $(15,25)$, its role in host APCs in GVHD pathogenesis is not clear. We found that C5aR expression was highly upregulated in splenic DCs after total body irradiation (TBI) as compared with that in naive mice (Supplemental Figure 1A; supplemental material available online with this article; https://doi.org/10.1172/ jci.insight.121697DS1). We also observed a lower number of residual DCs in the spleens of C3aR ${ }^{-/} /$ $\mathrm{C}_{5} \mathrm{aR}^{-/}$mice as compared with WT mice 1 day after TBI (Figure 1A), which was associated with reduced survival (Figure 1B) and increased apoptosis and death receptor Fas and FasL (Figure 1C and Supplemental Figure 1B). Autophagy is implicated in GVHD development after HCT (26). Lack of autophagy increases DC survival and allostimulatory capacity, leading to exacerbated GVHD (6). The engagement of C3aR/ $\mathrm{C} 5 \mathrm{aR}$ activates AKT signaling (27) that suppresses autophagy (22). We reasoned that the absence of C3aR/ $\mathrm{C} 5 \mathrm{aR}$ signaling would be associated with excessive autophagy that results in reduced survival and antigen-presenting capacity of DCs. Indeed, genetic deletion of $\mathrm{C} 3 \mathrm{aR} / \mathrm{C} 5 \mathrm{aR}$ increased the formation of the Cyto-ID autophagosome (Figure 1D) and expression of the representative autophagy marker LC3B in bone marrow-derived DCs (BM-DCs) (Figure 1E). Noticeably, p62 expression was slightly increased (Figure 1E), suggesting increased p62-mediated mitochondrial priming-dependent mitophagy in $\mathrm{C} 3 \mathrm{aR}^{-/-} / \mathrm{C}^{2} \mathrm{aR}^{-/} \mathrm{DCs}$ (28). Because autophagy is increased in DCs along with augmented death receptor Fas (29), we investigated whether blocking C3aR/C5aR could selectively increase lethal autophagy in DCs. TBI induces the translocation of LPS into gut lumen that activates DCs and promotes $\operatorname{GVHD}(30,31)$. We found that the colocalization of LTG (autophagosomal marker) and MTR (MitoTracker) was significantly increased in LPS-treated C3aR $\mathrm{aR}^{-/-} / \mathrm{C}^{\mathrm{a}} \mathrm{aR}^{-/-} \mathrm{DCs}$ (Figure $1 \mathrm{~F}$ ), supporting a higher mitophagy activity in $\mathrm{C} 3 \mathrm{aR}^{-/-} / \mathrm{C} 5 \mathrm{aR}^{-/-} \mathrm{DCs}$. Ceramide generation is responsible for the onset of mitophagy (32). Indeed, we detected a remarkable increase in the colocalization of ceramide and Tom 20, indicative of a greater mitochondrial fraction (Figure $1 \mathrm{G}$ ) in $\mathrm{C} 3 \mathrm{aR}^{-/-} / \mathrm{C}^{2} \mathrm{aR}^{-/-} \mathrm{DCs}$ following LPS stimulation. Ceramide can be generated by cerebrosidase, glucosylceramidase, or galactosylceramidase enzymes, which catalyze complex sphingolipid breakdown to ceramide (33). In this context, we found that the turnovers of sphingosine and glucosyl/galactosyl ceramides were substantially higher in LPS-treated C3aR ${ }^{-/} /$ $\mathrm{C}_{5} \mathrm{aR}^{-/-}$DCs compared with WT counterparts (Figure 2, A and B, and Supplemental Figure 1, D and E). 


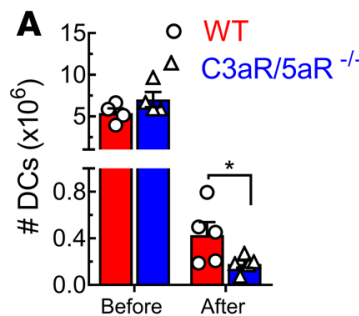

D

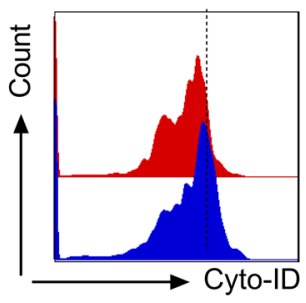

F WT

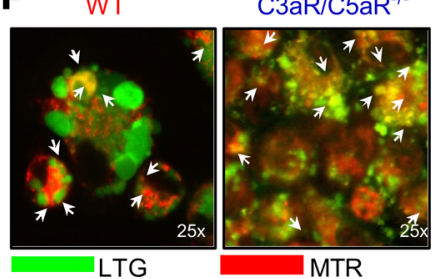

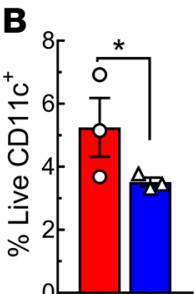
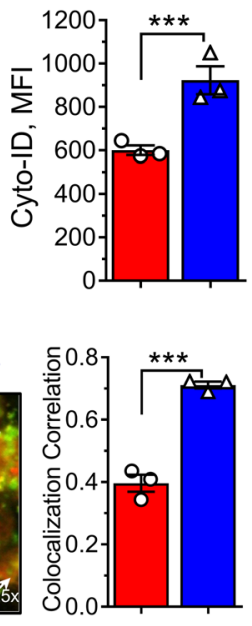
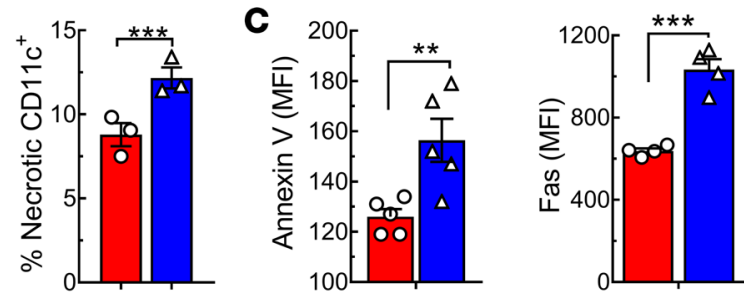

$\mathbf{E}$
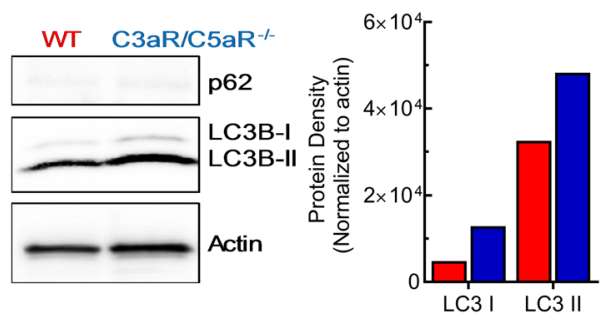

G
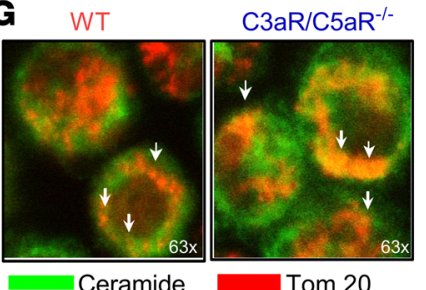

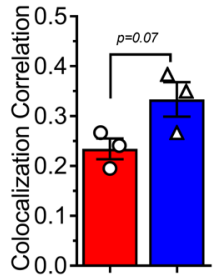

Figure 1. Complement $\mathrm{C} 3 \mathrm{aR} / \mathrm{C} 5 \mathrm{aR}$ signaling suppresses mitophagy that is required for survival and activation of host DCs after TBI. (A-E) WT and C3aR $\mathrm{R}^{-1-} / \mathrm{CS} \mathrm{aR}^{-1-}$ mice were irradiated at 700 cGy. (A) Quantification of splenic DCs

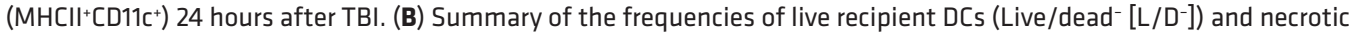
$\mathrm{DCs}\left(\mathrm{L} / \mathrm{D}^{+}\right.$Annexin $\left.\mathrm{V}^{+}\right)(n=4)$. (C) Summary graphs for the mean of fluorescence $(\mathrm{MFI})$ and representative histogram of annexin V and Fas. (D) Cyto-ID expression of splenic DCs $(n=3-4)$. (E) The protein expression of LC3B-I/LC3B-II and p62 of splenic DCs determined by Western blot. (F and $\mathbf{G}$ ) Irradiated BM-DCs were matured with $20 \mathrm{ng} / \mathrm{ml}$ LPS and were dual stained with MitoTracker red (MTR) and LysoTracker green (LTC) (original magnification, $\times 25$ ) (F) or with ceramide antibody and mitochondrial marker Tom20 (original magnification, $\times 63)$ (G). White arrows indicate colocalization $(n=$ 3). Unpaired 2-tailed $t$ test was used to compare between groups. Data were representative of 2 independent experiments and are presented as mean $\pm \mathrm{SEM} .{ }^{*} P<0.05,{ }^{* *} P<0.01,{ }^{* * *} P<0.001$.

We also observed that $\mathrm{C} 3 \mathrm{aR}^{-/-} / \mathrm{C}_{5} \mathrm{aR}^{-/-} \mathrm{DC}$ exhibited significantly increased proton leak (Figure $2 \mathrm{C}$ ), indicative of mitochondrial membrane damage (34) and reduced ATP coupling capacity (Figure 2, D and F). Nonmitochondrial OCR that indicates oxidative stress in cells (35) was also increased in $\mathrm{C}_{3 a R^{-1-} / \mathrm{C}^{2} \mathrm{aR}}^{-1-}$ DCs (Figure $2 \mathrm{E}$ ). In accordance with the higher death rate of $\mathrm{C}_{3} \mathrm{aR}^{-/} / \mathrm{C}^{2} \mathrm{aR}^{-/-} \mathrm{DCs}$, the mitochondrial reverse capacity depletion known to lead to cell death (36) was evident in $\mathrm{C} 3 \mathrm{aR}^{-/-} / \mathrm{C} 5 \mathrm{aR}^{-/-} \mathrm{DCs}$. In brief, these findings suggest that $\mathrm{C} 3 \mathrm{aR} / \mathrm{C} 5 \mathrm{aR}$ signaling is essential for host DC survival through suppressing lethal mitophagy after TBI.

C3aR/C5aR augments the activation and allostimulatory capacity of host DCs after transplantation. To investigate the role of $\mathrm{C} 3 \mathrm{aR} / \mathrm{C} 5 \mathrm{aR}$ in antigen presentation by DCs, we measured the expression of MHC-II and costimulatory receptors. We found that expression of MHCII and CD86 was significantly lower in $\mathrm{C} 3 \mathrm{aR}^{-/} / \mathrm{C} 5 \mathrm{aR}^{-/-} \mathrm{DCs}$ after TBI, suggesting a decrease in their activation and maturation status (Figure 3, $\mathrm{A}$ and $\mathrm{B})$. Host DCs are the most potent stimulator of donor T cells early after HCT (2). In the absence of C3aR/C5aR, host DCs were significantly reduced early after HCT (Figure 3C). At 4 days after TBI and cell transfer, splenic DCs secreted less IFN- $\gamma$ in $\mathrm{C} 3 \mathrm{aR}^{-1-} / \mathrm{C}^{2} \mathrm{aR}^{-/-}$recipients compared with WT recipients (Figure $3 \mathrm{D}$ ), reflecting less activation and likely reduced antigen-presenting capacity (37). Accordingly, $\mathrm{T}$ cell activation was lower in $\mathrm{C} 3 \mathrm{aR}^{-/-} / \mathrm{C} \mathrm{aR}^{-/-}$recipients, as demonstrated by a smaller percentage and absolute number of IFN- $\gamma^{+}$CD4 or CD8 T cells (Figure 3E). Donor T cells had increased levels of apoptosis and Fas expression (Figure $3 \mathrm{~F}$ ) in $\mathrm{C} 3 \mathrm{aR}^{-/-} / \mathrm{C} \mathrm{aR}^{-/-}$recipients. FasL expression was significantly upregulated in $\mathrm{C}_{3} \mathrm{aR}^{-/-} / \mathrm{C} 5 \mathrm{aR}^{-/-} \mathrm{DCs}$ (Supplemental Figure 1C). In contrast, the expression levels of the cell death marker DR5 and cell survival marker bcl-2 (Supplemental Figure 1, F and G) were unchanged, suggesting that Fas signaling is a primary pathway in promoting $\mathrm{T}$ cell death in $\mathrm{C} 3 \mathrm{aR}^{-/} / \mathrm{C}^{-1} \mathrm{aR}^{-/-}$recipients after $\mathrm{HCT}$. 
Sph-Cers

A

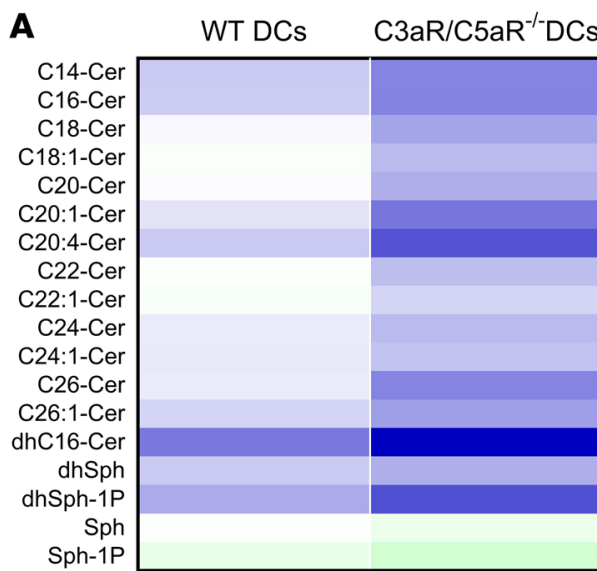

\section{Gal-Cers}

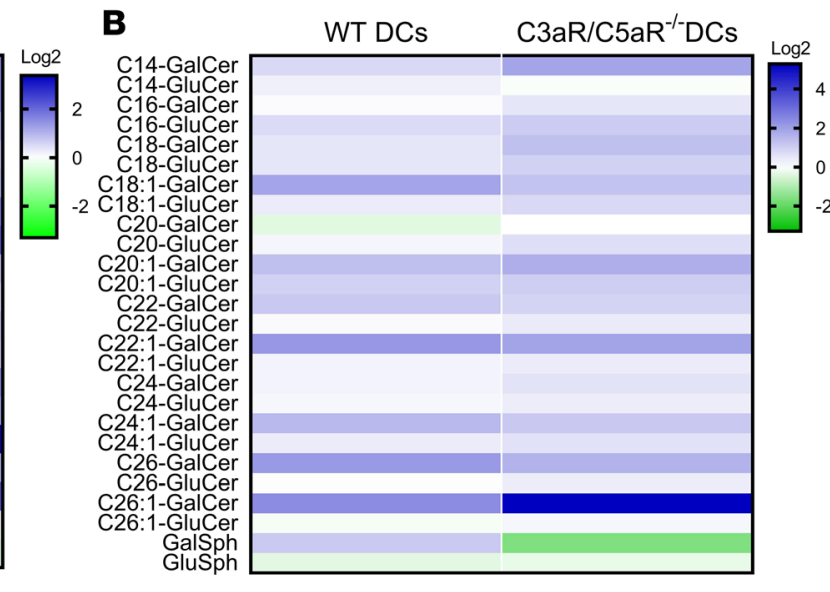

E

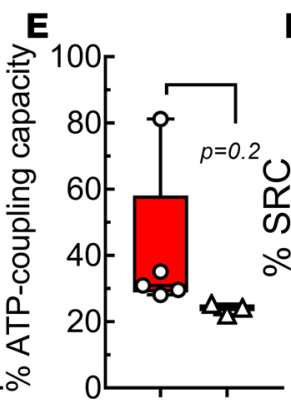

\section{$\mathbf{F}$}

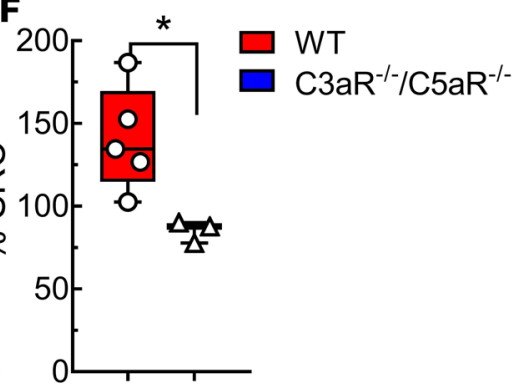

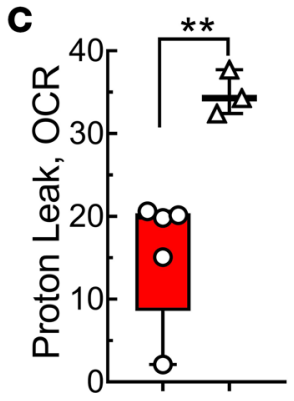

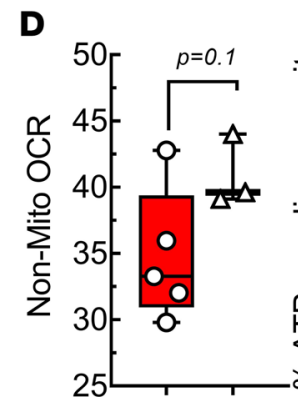

Figure 2. C3aR/C5aR signaling decreases ceramide trafficking in DCs. (A and B) Heatmaps present the $\log _{2}$ scale amount of regular ceramide (A) and glucosyl/galactosyl ceramide (B) in LPS-matured BM-DCs analyzed by HPLC-MS/MS analysis. (C-F) The oxygen consumption rate (OCR) of matured BM-DCs, including proton leak (C), nonmitochondrial respiration (D), spare respiration capacity (E), and ATP-coupling capacity (F). Unpaired 2-tailed $t$ test was used to compare between groups. Data are presented as mean \pm SD $(n=3-5) .{ }^{*} P<0.05,{ }^{* *} P<0.01$.

Taken together, these data indicate that $\mathrm{C} 3 \mathrm{aR} / \mathrm{C} 5 \mathrm{aR}$ regulates the survival and stimulatory capacity of recipient DCs via attenuating their mitophagy activity.

Regulation of GVHD development after HCT by targeting host C3aR/C5aR. Since allostimulation of donor $\mathrm{T}$ cells by recipient DCs is critical for the initiation of GVHD (38), targeting C3aR/C5aR signaling in the host may effectively prevent GVHD development after HCT. The immunological phenotypes of WT and $\mathrm{C} 3 \mathrm{aR}^{-/-} / \mathrm{C} 5 \mathrm{aR}^{-/-}$age-matched mice were similar (Supplemental Figures 2 and 3). In FVB $\left(\mathrm{H} 2^{\mathrm{q}}\right) \rightarrow \mathrm{B} 6$ $\left(\mathrm{H} 2^{b}\right)$ and $\mathrm{B} 6\left(\mathrm{H} 2^{\mathrm{b}}\right) \rightarrow \mathrm{BALB} / \mathrm{c}\left(\mathrm{H} 2^{\mathrm{d}}\right)$ models, we consistently found that $\mathrm{C} 3 \mathrm{aR}^{-1-} / \mathrm{C}_{5} \mathrm{aR}^{-/-}$recipient mice displayed significantly milder GVHD as compared with WT recipients, reflected by prolonged survival (Figure 4, A and C) and significantly lower clinical scores (Figure 4, B and D). C3aR $\mathrm{aR}^{-/ /} \mathrm{C} 5 \mathrm{aR}^{-/-}$recipients consistently displayed better thymic regeneration and donor-derived $\mathrm{B} 220^{+} \mathrm{B}$ cell and CD4 and CD 8 $\mathrm{T}$ cell reconstitution in recipient spleens (Figure $4 \mathrm{E}$ ). In line with GVHD severity, levels of proinflammatory cytokines TNF- $\alpha$, IFN- $\gamma$, IL- 6 , and IL-17 were decreased in the sera of C3aR $\mathrm{R}^{-/-} / \mathrm{C}_{5} \mathrm{aR}^{-/-}$recipients compared with WT recipients 14 days after HCT (Figure 4F). Interestingly, host C3aR/C5aR deficiency also reduced the severity of a cutaneous chronic model of GVHD B10D2 $\rightarrow$ BALB/c (Supplemental Figure 4, A and B). In summary, $\mathrm{C} 3 \mathrm{aR} / \mathrm{C} 5 \mathrm{aR}$ in the host hematopoietic compartment is required for optimal induction of GVHD after HCT.

C3aR/C5aR expressed in recipient hematopoietic cells is mainly responsible for the initiation of GVHD after $H C T$. As C3aR/C5aR is expressed on both hematopoietic and nonhematopoietic APCs (15), which are known to contribute to the development of GVHD (39), we next evaluated the contribution of C3aR/ C5aR in either compartment to GVHD. We generated 4 types of BM chimeric mice where C3aR/C5aR was absent in the hematopoietic compartment, the nonhematopoietic compartments, or both (Supplemental Figure 5). Using these BM chimeras as recipients, we observed that severe GVHD was induced in the chimeras where $\mathrm{C} 3 \mathrm{aR} / \mathrm{C} 5 \mathrm{aR}$ was intact in recipient hematopoietic system but a significantly milder GVHD was induced in the chimeras where $\mathrm{C} 3 \mathrm{aR} / \mathrm{C} 5 \mathrm{aR}$ was absent in recipient hematopoietic 
A

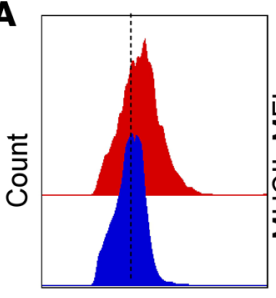
$\mathrm{MHCll}$

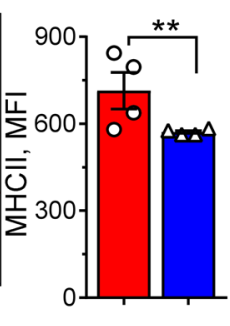

C
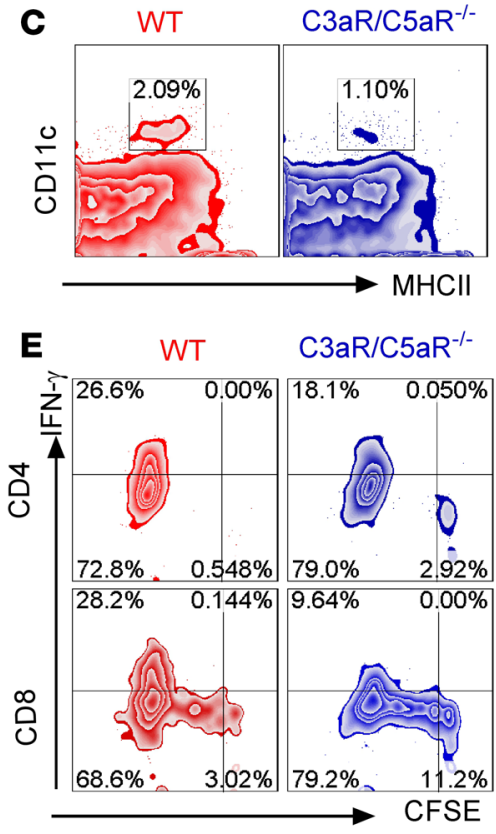

B

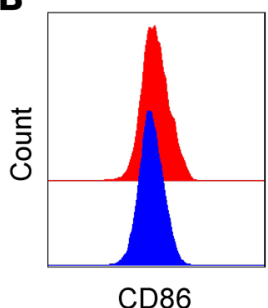

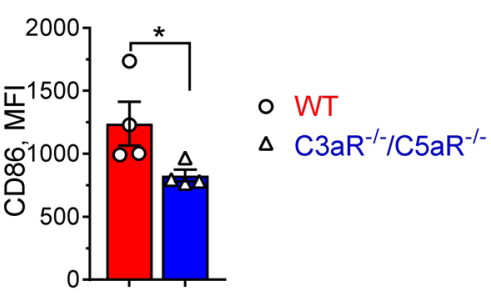

D
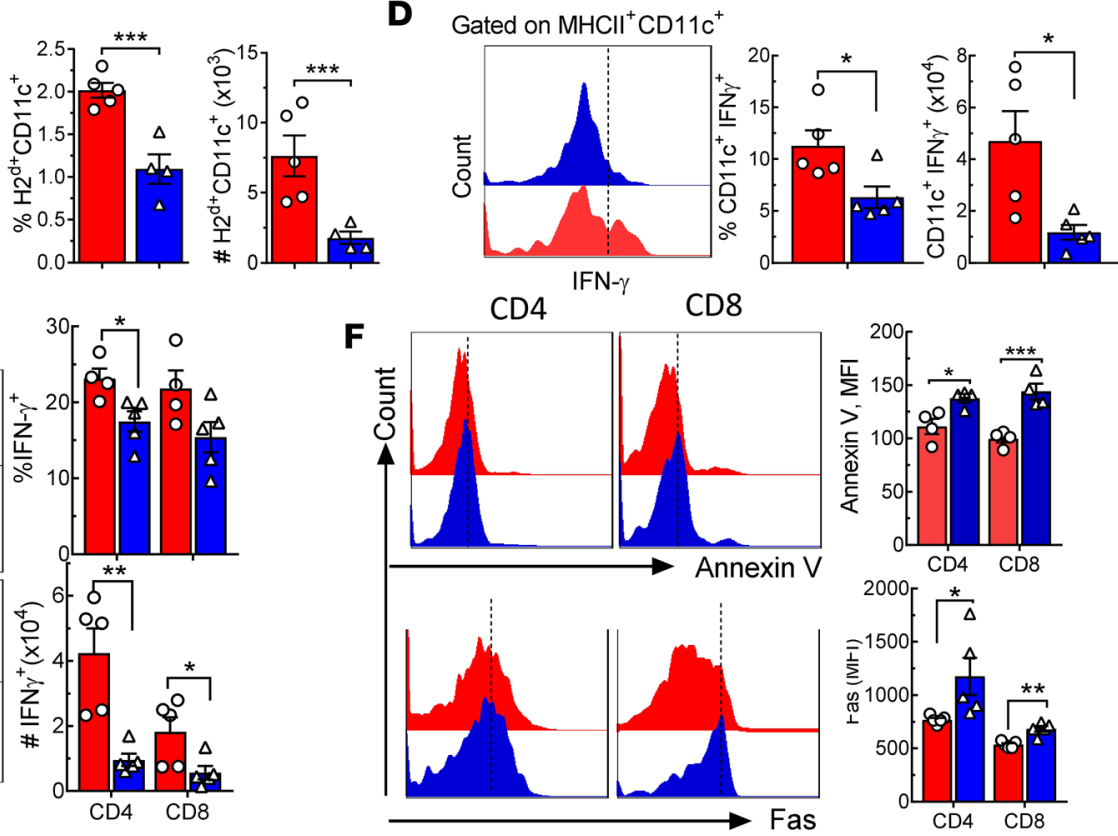

Figure 3. C3aR/C5aR increases activation and allostimulatory capacities of DCs after HCT. (A) WT or C3aR $\mathrm{R}^{-1-} / \mathrm{C5}$ aR ${ }^{-/-}$BALB/C mice were lethally irradiated and euthanized 24 hours later. Representative histograms of frequencies for MHCII (A) and CD86 (B) of CD11c ${ }^{+}$splenic cells. (C-F) Lethally irradiated WT or $\mathrm{CBaR}^{-1-} / \mathrm{C} 5 \mathrm{aR} \mathrm{R}^{-1-} \mathrm{BALB} / \mathrm{c}$ recipients were transplanted with CFSE-labeled T cells. Four days later, splenic cells were analyzed. (C) Representative zebra plots, histograms, or summary bar graphs for splenic $\mathrm{H}^{\mathrm{d}+}{ }^{+} \mathrm{CD} 11 \mathrm{c}^{+} \mathrm{MHCII}{ }^{+}$cells (D) the frequencies and the numbers of recipient DCs and CD11c $\mathrm{I}^{+} \mathrm{FN}-\gamma^{+}$cells from WT and $\mathrm{CZaR}^{-1-} / \mathrm{CSaR}^{-1-}$ recipients, (E) donor CD4+IFN- $\gamma^{+}$and CD8 ${ }^{+} \mathrm{IFN}-\gamma^{+}$cells with low/high expression of CFSE, and (F) the expression of annexin $\mathrm{V}$ and Fas in $\mathrm{H}^{\mathrm{b}+}{ }^{\mathrm{CD}} 4^{+}$and $\mathrm{CD} 8^{+} \mathrm{T}$ cells. Unpaired 2-tailed $t$ test $(\mathbf{A}-\mathbf{D})$ and Wilcoxon rank-sum test $(\mathbf{E}$ and $\mathbf{F})$ were used to compare between groups. Data are presented as mean $\pm \operatorname{SEM}(n=4-5) .{ }^{*} P<0.05,{ }^{* *} P<0.01,{ }^{* *} P<0.001$.

system (Figure 4, $\mathrm{G}$ and $\mathrm{H}$ ). These results demonstrate that $\mathrm{C} 3 \mathrm{aR} / \mathrm{C} 5 \mathrm{aR}$ in the recipient hematopoietic, but not nonhematopoietic, compartment plays a significant role in the induction of GVHD.

C3aR ${ }^{-/-} / C 5 a R^{-/-}$DCs effectively prevent GVHD development after HCT via inducing DC mitophagy activity. To confirm the role of C3aR/C5aR expressed in DCs to GVHD development after HCT, we cotransplanted $\mathrm{C} 3 \mathrm{aR}^{-/-} / \mathrm{C} 5 \mathrm{aR}^{-/-} \mathrm{DCs}$ along with donor grafts. In BM-DCs, autophagy activity was markedly higher in the absence of C3aR/C5aR (Supplemental Figure 4C). DC reconstitution was about $90 \%$ of total CD $11 \mathrm{c}^{+}$host cells 3 days after HCT (Supplemental Figure 4D). Cotransfer of C3aR $\mathrm{aR}^{-/-} / \mathrm{C} \mathrm{aR} \mathrm{R}^{-/-} \mathrm{DCs}$ reduced GVHD mortality and morbidity (Figure 4, I and J), supporting a critical role for C $3 \mathrm{aR} / \mathrm{C} 5 \mathrm{aR}$ on DCs in GVHD pathogenicity. Interestingly, recipients cotransferred with host $\mathrm{C} 3 \mathrm{aR}^{-/-} / \mathrm{C} \mathrm{aR}^{-/-} \mathrm{DCs}$ also demonstrated a better survival rate and lower GVHD clinical score as compared with those without DC cotransfer (Figure 4, I and J). Similar results were also observed in the B6 $\rightarrow$ BALB/c HCT model (Supplemental Figure 4, E and F). These results suggest that $\mathrm{C} 3 \mathrm{aR}^{-1-} / \mathrm{C}^{2} \mathrm{aR}^{-1-} \mathrm{DC}$ but not WT DCs play a regulatory role in GVHD development.

As DCs deficient for C3aR/C5aR underwent greater mitophagy (Supplemental Figure 4C), we asked whether mitophagy is required for the regulatory function of $\mathrm{C} 3 \mathrm{aR}^{-/-} / \mathrm{C} 5 \mathrm{aR}^{-1-} \mathrm{DCs}$. To this end, we cultured BM-DCs with an autophagy inhibitor, hydroxychloroquine (HQ), currently used in the clinic (40, 41) and confirmed that the inhibitor reduced autophagy activity of $\mathrm{C} 3 \mathrm{aR}^{-/-} / \mathrm{C}^{2} \mathrm{aR}^{-/-} \mathrm{DCs}$ to be comparable with WT DCs (Supplemental Figure 4C). Upon DC cotransfer, HQ-treated C3aR $\mathrm{a}^{-/-} / \mathrm{C}_{5} \mathrm{aR}^{-/-} \mathrm{DCs}$ 
A
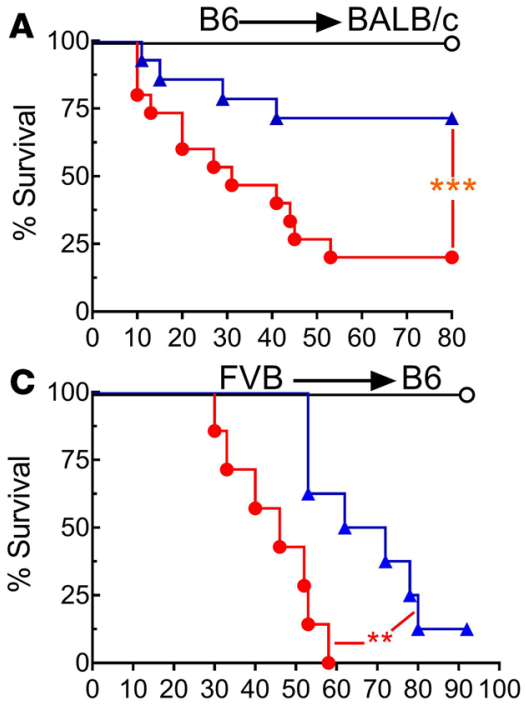

E

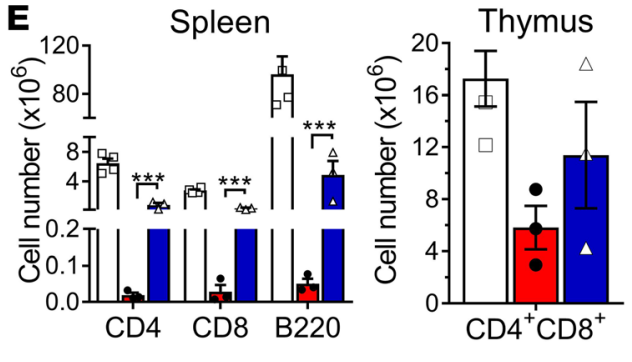

G
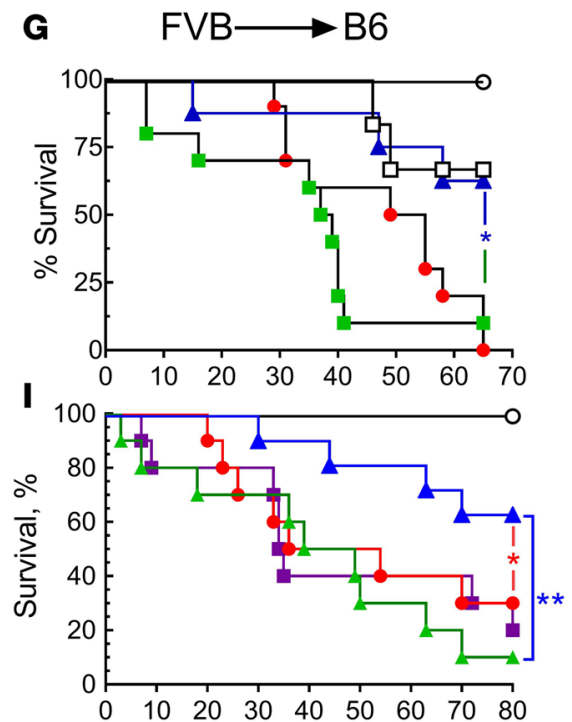

Days after HCT

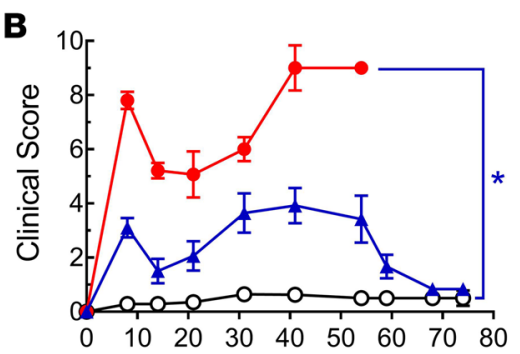

\section{D}

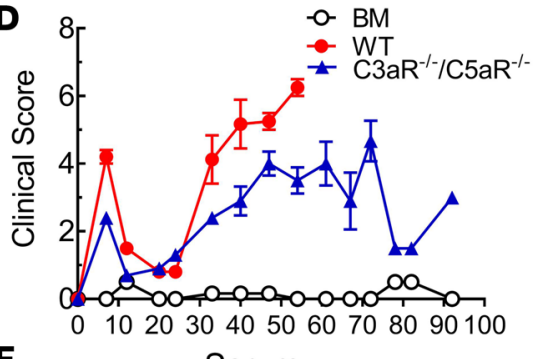

F

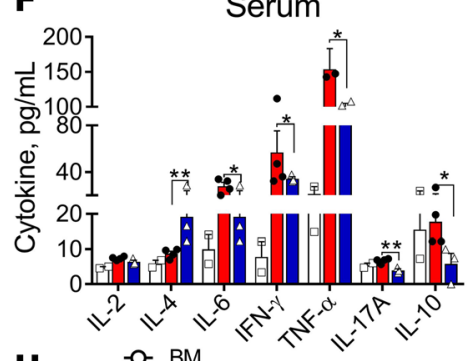

H
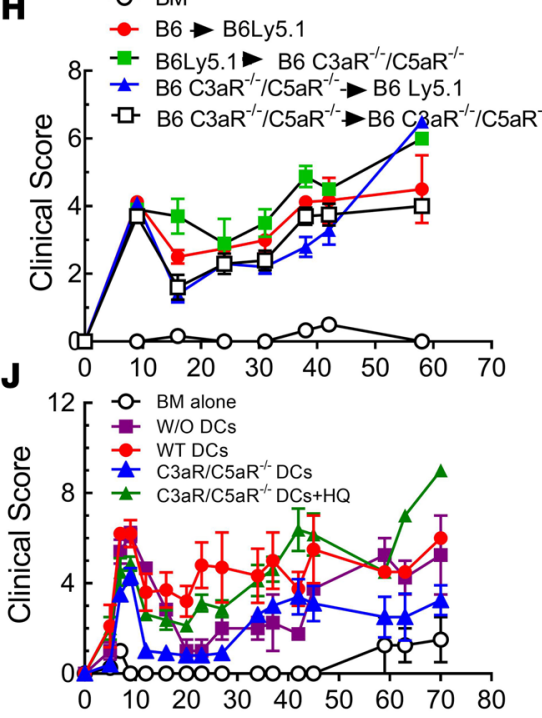

Days after HCT
Figure 4. C3aR/C5aR deficiency of recipients ameliorates CVHD via increasing lethal mitophagy in recipient DCs. (A and B) Lethally irradiated WT or $\left[3 a R^{-1-} /\left[5 \mathrm{aR}^{-1-} \mathrm{BALB} / \mathrm{c}\right.\right.$ recipients ( $n=12-15)$ were transplanted with TCDBM $\left(5 \times 10^{6} /\right.$ mouse) with or without T cells $\left(1 \times 10^{6} /\right.$ mouse) from B6 mice and monitored for survival (A) and clinical scores (B). (C and D) B6 recipients were transplanted with $\mathrm{BM}\left(5 \times 10^{6} /\right.$ mouse $)$ plus purified T cells $\left(1 \times 10^{6} /\right.$ mouse $)$ from FVB donors $(n=7-10)$. Survival (C) and clinical score (D) are shown. (E and F). Spleens and thymi were isolated from transplanted recipients in $\mathbf{A} 80$ days after HCT. (E) The number of CD4 ${ }^{+}$CD8 ${ }^{+}$cells in the thymi and of donor CD4, CD8, and B220 cells in the spleens $(n=3)$. (F) The levels of cytokine in recipient sera 14 days after $\mathrm{HCT}(n=$ 2-3). (G and $\mathbf{H}$ ) Lethally chimeras B6 recipients ([WT $\rightarrow \mathrm{WT}]$, [WT $\rightarrow\left[3 \mathrm{CR}^{-1-} /\right.$ $\left[5 \mathrm{aR}^{-/-}\right],\left[\mathrm{C3aR}^{-/-} / \mathrm{C}^{2} \mathrm{aR}^{-/-} \rightarrow \mathrm{WT}\right]$, and $\left.\left[\mathrm{C3aR}^{-1-} / \mathrm{C5}_{\mathrm{aRR}}^{-1-} \rightarrow \mathrm{CHaR}^{-1-} / \mathrm{C5aR}^{-1-}\right]\right)$ were transplanted with $\mathrm{BM}$ alone $(5 \times$ $10^{6} /$ mouse) or BM plus purified T cells ( 2 $\times 10^{6}$ /mouse) from FVB donors. Survival (G) and clinical score $(\mathbf{H})$ are shown ( $n$ $=10$ ). (I and J) Lethally irradiated B6 recipients ( $n=10-12$ /group) were transplanted with BM $\left(3 \times 10^{5} /\right.$ mouse $)$ plus purified T cells $\left(1 \times 10^{6} /\right.$ mouse $)$ from FVB donors. Recipients also received 2

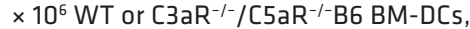
previously cultured overnight with hydroxyl chloroquine (HQ) $(5 \mathrm{mg} / \mathrm{ml})$, on the transplanted day. Survival (I) and clinical score (J) are shown. The log-rank (Mantel-Cox) test (A, C, G, and I), nonparametric Mann-Whitney $U$ test (B, D, $\mathbf{H}$, and $\mathbf{J}$ ), and unpaired $t$ test (E and $\mathbf{F}$ ) were used to compare between groups. Data are represented as mean \pm SEM. ${ }^{*} P$ $<0.05,{ }^{* *} P<0.01,{ }^{* * *} P<0.001$.

were no longer able to reduce GVHD severity (Figure 4, I and J), indicating that mitophagy was required for the protective effect of $\mathrm{C} 3 \mathrm{aR}^{-/-} / \mathrm{C} 5 \mathrm{aR}^{-/-} \mathrm{DCs}$ in GVHD.

Host C3aR/C5aR deficiency increases donor $T$ cell apoptosis and decreases their migration capacity toward GVHD target organs. The numbers of donor CD4 and CD8T cells were significantly decreased in the livers of $\mathrm{C}_{3} \mathrm{aR}^{-/} / \mathrm{C} 5 \mathrm{aR}^{-/-}$recipients compared with WT recipients (Figure $5 \mathrm{~A}$ ). This could be due to decreased survival, expansion, and/or migration. Chemokine receptors are known to support the migration of pathogenic $\mathrm{T}$ cells to the target organs (42). Indeed, donor $\mathrm{T}$ cells in the spleens of $\mathrm{C} 3 \mathrm{aR}^{-1-}$ $\mathrm{C} \mathrm{aR}^{-/-}$recipients displayed lower expression of liver/gut-homing receptors CXCR3 and CCR6 (Supplemental Figure 6, A-C) in $\mathrm{C} 3 \mathrm{aR}^{-1-} / \mathrm{C}_{5} \mathrm{aR}^{-/-}$recipients compared with WT counterparts. Donor $\mathrm{T}$ cells 
also displayed significantly lower staining for $\mathrm{Ki} 67$ in the livers of $\mathrm{C} 3 \mathrm{aR}^{-/-} / \mathrm{C} 5 \mathrm{aR}^{-/-}$recipients, suggesting that they proliferated less in $\mathrm{C}_{3} \mathrm{aR}^{-/-} / \mathrm{C} \mathrm{aR}^{-/}$recipients (Supplemental Figure $6, \mathrm{D}$ and $\mathrm{E}$ ). In contrast, donor $\mathrm{T}$ cell proliferation was similar in recipient spleens regardless of $\mathrm{C} 3 \mathrm{aR} / \mathrm{C} 5 \mathrm{aR}$ expression (Figure 5B), as reflected by CFSE dilution (Figure 3E) and Ki67 expression (Supplemental Figure 6, D and F). Therefore, alleviated GVHD in $\mathrm{C} 3 \mathrm{aR}^{-/-} / \mathrm{C} \mathrm{aR}^{-/-}$recipients is correlated with reduced donor $\mathrm{T}$ cells proliferation and migration in GVHD target organs.

Host C3aR/C5aR is required for glycolytic activity and Th1/Th17 differentiation of donor T cells after HCT. Glycolysis is required for donor T cells to induce GVHD (43). C3a/C5a secreted from DCs can act in an autocrine manner to further amplify their generation during the cognate interaction with $\mathrm{T}$ cells, which can affect $\mathrm{T}$ cell metabolism (25). Indeed, glycolytic activity, but not oxidative phosphorylation, of donor $\mathrm{T}$ cells in $\mathrm{C} 3 \mathrm{aR}^{-1-} / \mathrm{C} 5 \mathrm{aR}^{-/-}$recipients was impaired (Figure 5, C and D). C3aR/C5aR signaling is required for $\mathrm{T}$ cells to differentiate into Th1/Th17 cells that are pathogenic in GVHD (17). At 14 days after HCT, the percentage and absolute numbers of IFN- $\gamma$-secreting CD4 and CD8 donor T cells were significantly lower in the livers (Figure 5, E and F), but not in spleens (Supplemental Figure 6, A and $\mathrm{B}$ ), of $\mathrm{C} 3 \mathrm{aR}^{-/-} / \mathrm{C} 5 \mathrm{aR}^{-/-}$recipients. Although the percentages of donor IL-4/5- and IL-17-secreting cells were comparable, the total numbers of these cell subsets were significantly decreased in the livers of $\mathrm{C} \mathrm{aR}^{-/-} / \mathrm{C} \mathrm{aR}^{-/}$recipients versus WT controls (Figure $5, \mathrm{E}-\mathrm{H}$ ). In contrast, the percentage and absolute numbers of Tregs were remarkably increased in spleens of $\mathrm{C}_{3} \mathrm{aR}^{-1-} / \mathrm{C}_{5} \mathrm{aR}^{-1-}$ recipients (Figure $5, \mathrm{I}-\mathrm{K}$ ). There were no differences in the percentage of IL-4/5-secreting T cells in the spleens between these two groups (Supplemental Figure 7, A and C). Altogether, these results indicated that, in the absence of host $\mathrm{C} 3 \mathrm{aR} / \mathrm{C} 5 \mathrm{aR}$, donor $\mathrm{T}$ cells have a reduced capacity to differentiate into an effector $\mathrm{T}$ cells phenotype (Th1/Tc1), while enhancing their differentiation into Tregs specifically in GVHD target organs.

Host C3aR/C5aR is required for optimal GVL activity. Since the primary purpose of HCT is to treat hematologic malignancy, we evaluated the role of $\mathrm{C} 3 \mathrm{aR} / \mathrm{C} 5 \mathrm{aR}$ in maintaining GVL activity after HCT. While donor $\mathrm{T}$ cells induced less severe $\mathrm{GVHD}$ in $\mathrm{C} 3 \mathrm{aR}^{-1-} / \mathrm{C} \mathrm{aR}^{-/-}$recipients, they also mediated weaker GVL activity (Supplemental Figure 8). These results suggest that $\mathrm{C} 3 \mathrm{aR} / \mathrm{C} 5 \mathrm{aR}$ expression in the host is required for donor T cells to exert an optimal GVL effect.

Preventative treatment with C3aRA / C5RA preserves GVL activity. Given the short life of recipient DCs after HCT (44), blocking C3aR/C5aR in the host for a short period of time may effectively prevent GVHD while preserving the GVL effect. A combination of C3aR and C5aR antagonists (C3aRA/ C5aRA) augmented ceramide-associated mitophagy in DCs, as indicated by increased colocalization of ceramide and Tom20 (Supplemental Figure 9A). We then performed a single injection of $\mathrm{C} 3 \mathrm{aRA} / \mathrm{C} 5 \mathrm{aRA}$ to the recipients 1 day before HCT to exclude their effect on donor T cells. As a result, C3aRA/C5aRA treatment significantly attenuated GVHD, while maintaining sufficient a GVL activity against A20 lymphoma (Figure 6, A-D) and a more aggressive tumor of multiple lineage leukemia (MLL) (Figure 6, F and G, and Supplemental Figure 9B). Importantly, C3aRA/C5aRA treatment also prolonged recipient survival against Raji lymphoma in a human-to-mouse xenograft GVHD model (Figure 6, H and I).

Donor CD8 T cells play a dominant role in mediating the GVL effect via their CTL activity (45). We explored the mechanisms by which prophylactic treatment with C3aR/C5aR antagonists preserved GVL activity, when this did not occur in genetic depletion of C3aR/C5aR (Supplemental Figure 8). At 30 days after $\mathrm{HCT}$, the expression of granzyme B, perforin, and CD107a were not affected by the temporary blockade of $\mathrm{C} 3 \mathrm{aR} / \mathrm{C} 5 \mathrm{aR}$ in WT recipients. In contrast, the CTL activity of CD8 T cells was severely impaired in $\mathrm{C}_{3} \mathrm{aR}^{-/-} / \mathrm{C} \mathrm{aR}^{-/-}$recipients (Figure $6 \mathrm{E}$ and Supplemental Figure 9C). Therefore, the impairment of CTL function is likely an important factor that dictates the GVL effect against tumor relapse.

\section{Discussion}

In the current study, we found that suppression of ceramide-dependent lethal mitophagy (CDLM) mediated by $\mathrm{C} 3 \mathrm{aR} / \mathrm{C} 5 \mathrm{aR}$ signaling was critical for GVHD development after HCT. We also reported that targeting recipient $\mathrm{C} 3 \mathrm{aR} / \mathrm{C} 5 \mathrm{aR}$ by a prophylactic treatment with C3aRA/C5aRA effectively spared GVHD and the GVL effect after HCT. Although autophagy induction in transplanted recipients after TBI has been reported (6), the cell subset and molecular mechanisms that mediate autophagy are largely unknown. We identified that TBI selectively induced lethal mitophagy in DCs via suppressing C3aR/C5aR signaling after HCT. In the absence of C3aR/C5aR, mitophagy accelerated ROS generation, mitochondrial damage, 
A

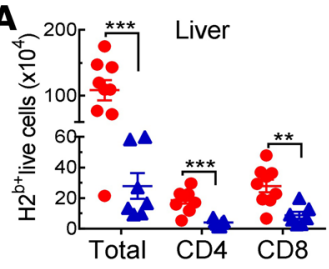

C

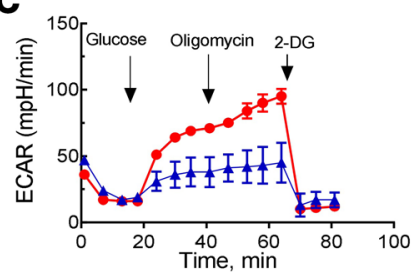

E
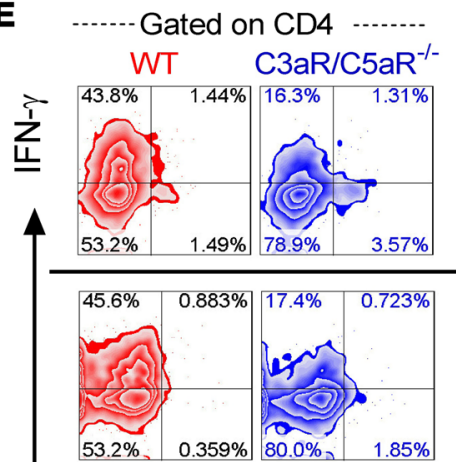

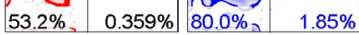

B

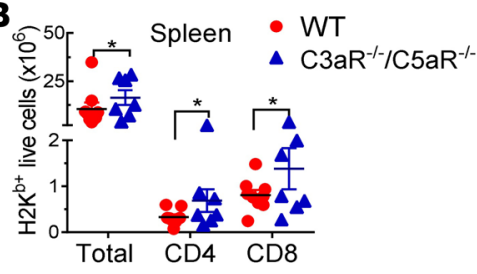

D

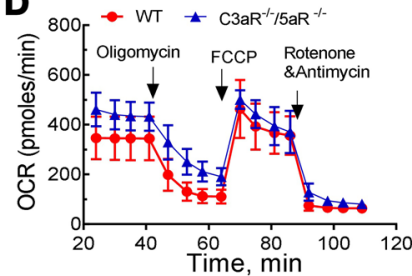

Gated on CD8

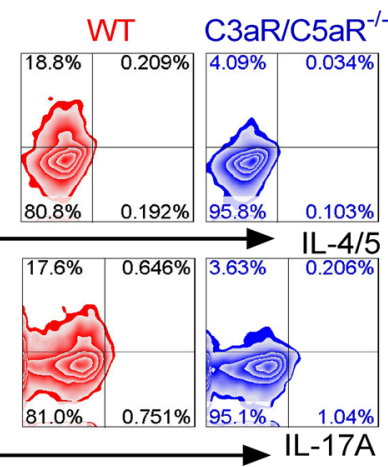

F

F
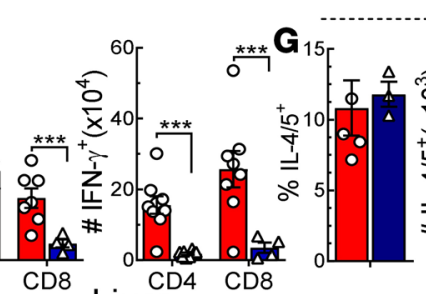

Gated on CD4

\section{I}
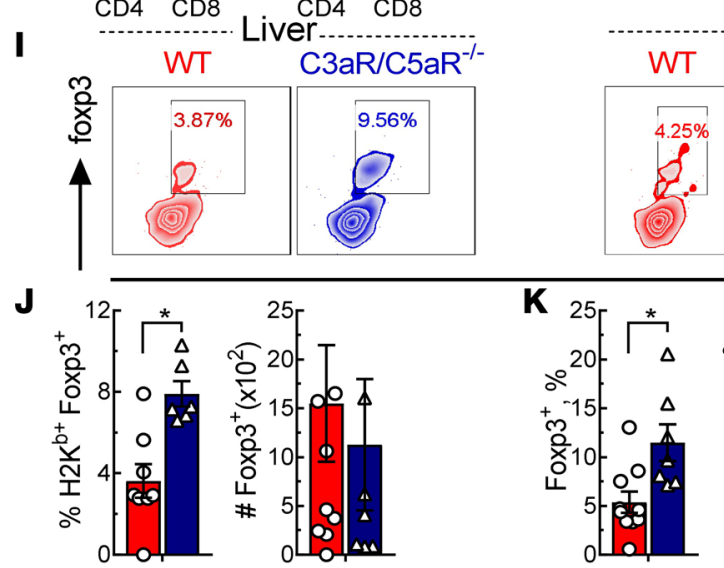

Spleen

$\mathrm{C} 3 \mathrm{aR} / \mathrm{C} \mathrm{aR}{ }^{-1-}$

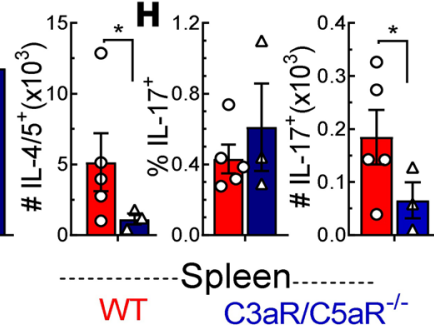

$24.9 \%$
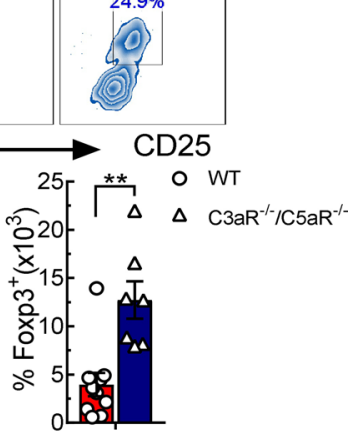

and ceramide trafficking, which subsequently impaired allostimulatory activity of DCs. Antigen-presenting activity of recipient DCs is critical in GVHD induction (44). The present study clearly showed that upregulation of lethal mitophagy in DCs effectively prevents GVHD development after HCT. Mechanistically, $\mathrm{C} 3 \mathrm{aR} / \mathrm{C} 5 \mathrm{aR}$ signaling is required for host DC and donor T cell survival. During cognate interactions, both donor $\mathrm{T}$ cells and recipient DCs produce $\mathrm{C} 3 \mathrm{a} / \mathrm{C} 5 \mathrm{a}$ (16). The present study demonstrated that $\mathrm{C} 3 \mathrm{a} / \mathrm{C} 5 \mathrm{a}$ generated by DCs, and amplified through an autocrine manner, is essential for donor T cell activation after HCT. Chronic activation of donor T cells by alloantigen may be responsible for the C3a/C5a amplification. This result is in accordance with the report that C3a/C5a mRNA is produced in $\sim 1000$-fold excess 

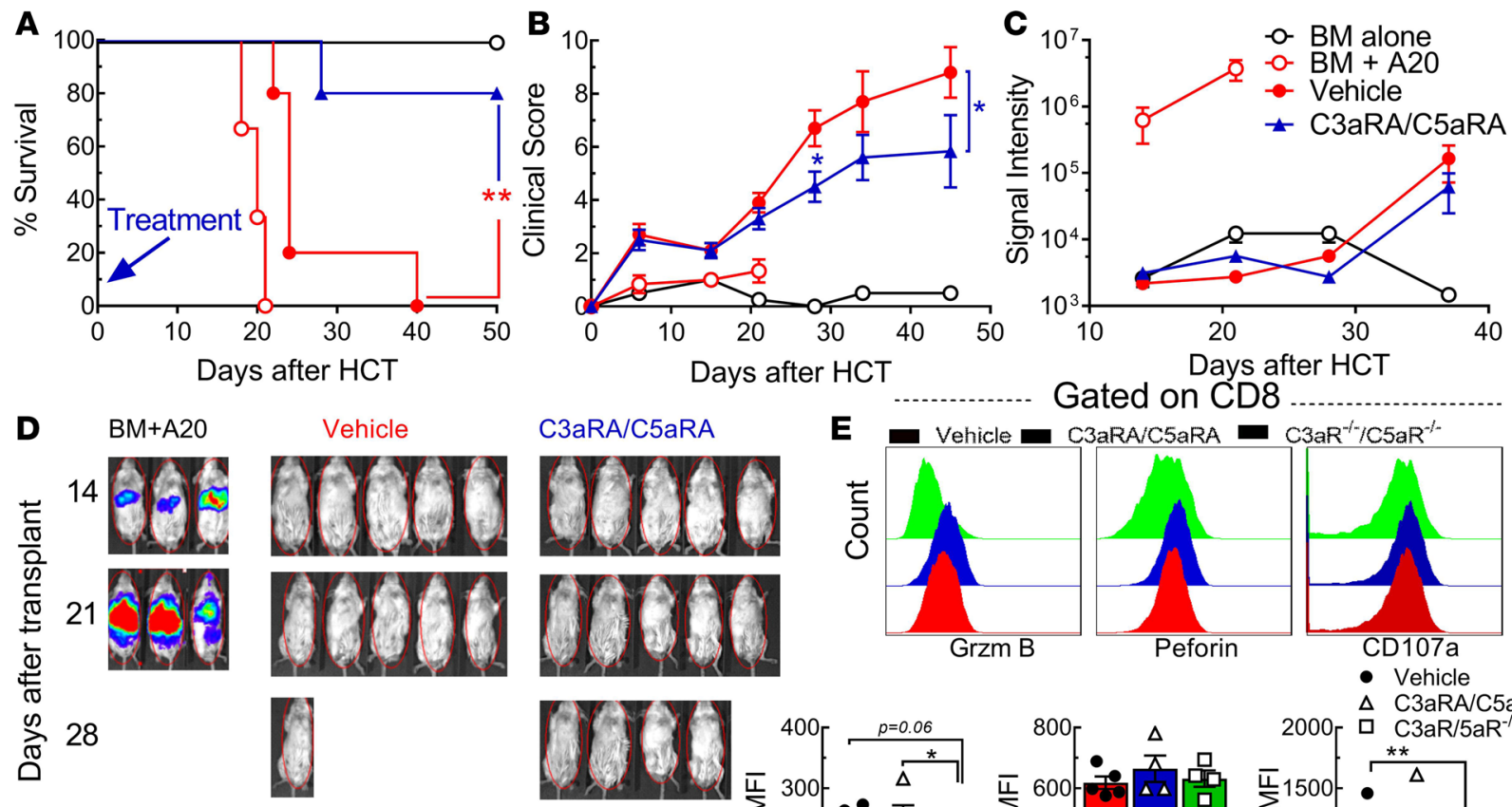

C3aRA/C5aRA
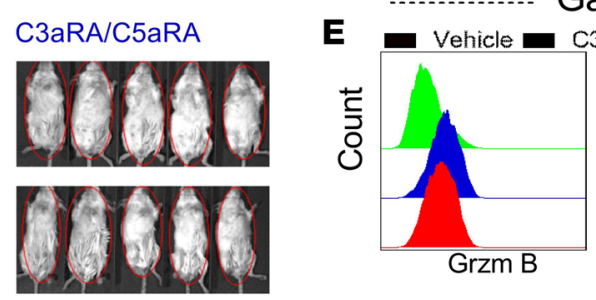

Gated on CD8

C3aRA/C5aRA $=\mathrm{CBaR}^{-1 /} / \mathrm{CS}_{\mathrm{aR}} / \%$

37
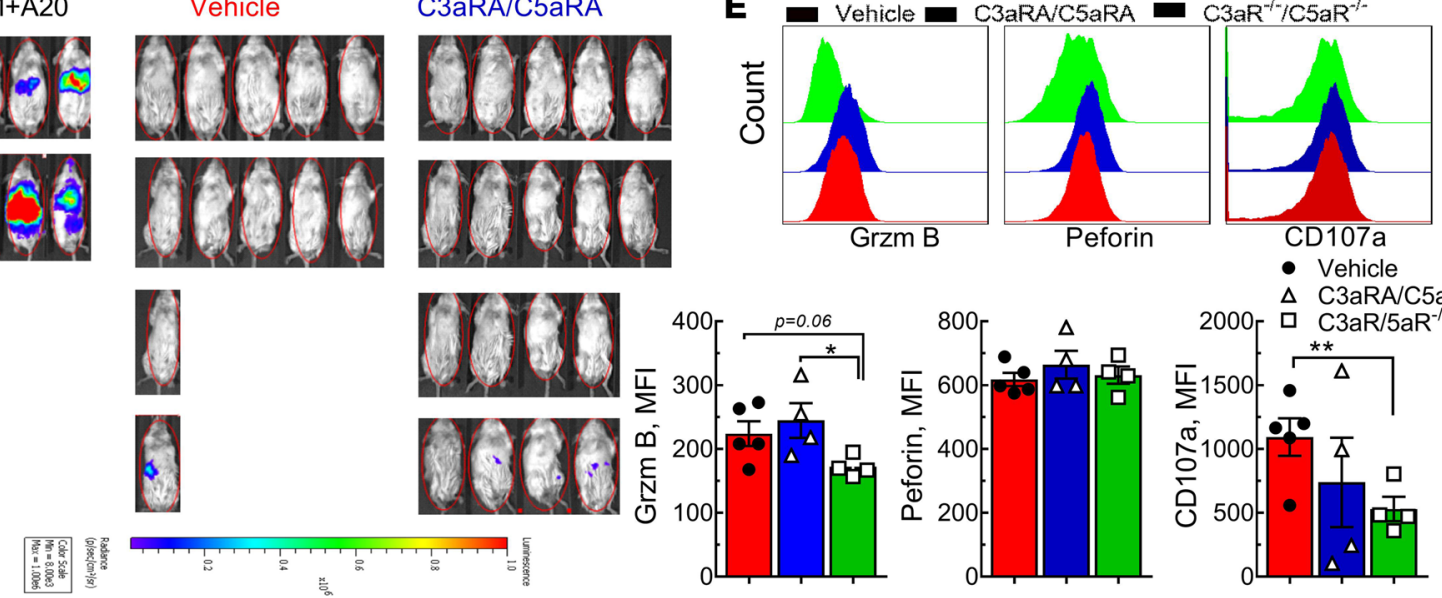

$\Delta$ C3aRA/C5aRA

F $\quad \mathrm{B} 6 \rightarrow \mathrm{BALB} / \mathrm{C}$

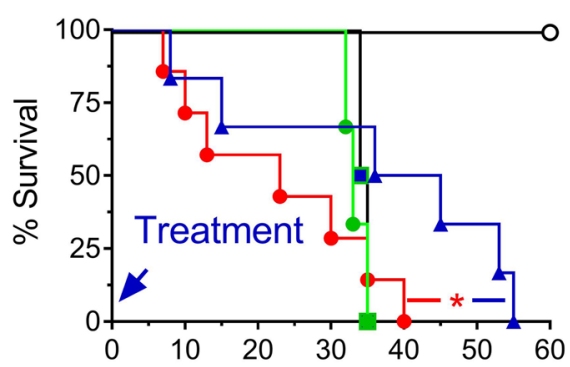

H Human-xenograft GVHD

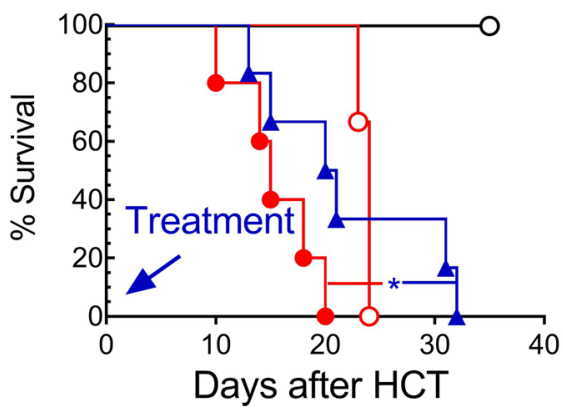

G

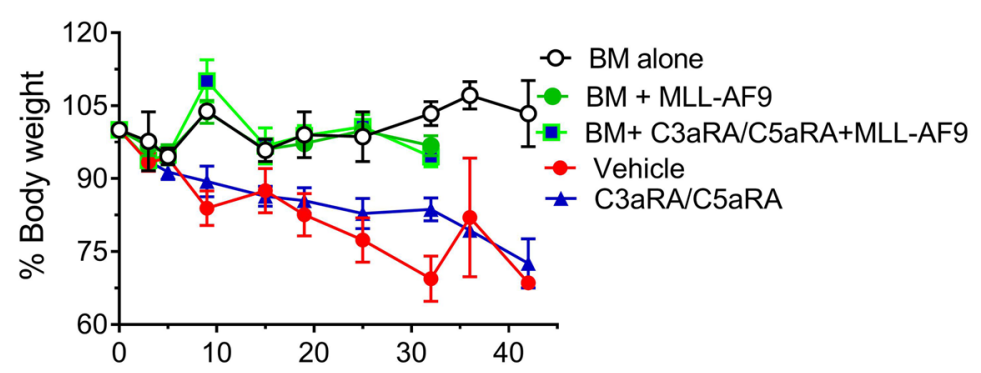

I

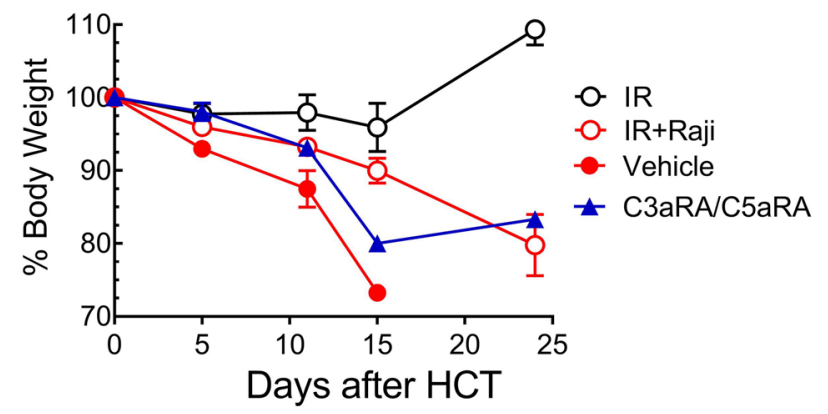

Figure 6. Preventative treatment with antagonist combination (C3aRA/C5aRA) reduces GVHD while preserving GVL activity. (A-E) BALB/C recipients $(n=5-7)$ were treated i.p. with C3RA ( $2 \mathrm{mg} / \mathrm{kg})$ and C5aRA $(1 \mathrm{mg} / \mathrm{kg})$ after TBI on day -1 and transplanted with TCD-BM $\left(5 \times 10^{6} / \mathrm{mouse}\right)$ and T cells $(1 \times$ $10^{6}$ /mouse) from B6 WT donors and A20 tumor cells. Survival (A), clinical score (B), and tumor signal (C and D). In a separate experiment, on day 30 after transplant, splenic cells were isolated from the recipients. (E) Representative histograms and summary graphs for MFI of grzm B, perforin, and CD107a expression. (F and $\mathbf{G})$ HCT was performed with recipients that received MLL-AF9 cells. Survival $(\mathbf{F})$ and body weight $(\mathbf{G})(n=8)$. NSG-A2 mice were irradiated (280 cGy), treated with C3RA/C5aRA, and transfused with HLA-A2- PBMCs $\left(15 \times 10^{6}\right)$ and Raji cells $\left(1 \times 10^{6} /\right.$ mouse). Survival (H) and body weight (I) $(n=5-7)$. The log-rank (Mantel-Cox) test $(\mathbf{A}, \mathbf{F}$, and $\mathbf{H})$, nonparametric Mann-Whitney $U$ test (B, C, $\mathbf{G}$, and $\mathbf{I})$, and unpaired 2 -tailed $t$ test (E) were used to compare between groups. Data are presented as mean \pm SEM. ${ }^{*} P<0.05,{ }^{* *} P<0.01,{ }^{* * *} P<0.001$. 
by APCs compared with T cells after activation (21). Our results suggest that targeting lethal mitophagy or ceramide metabolism-mediated enzymes in DCs may be an effective strategy to control GVHD. However, it is questionable whether other mitophagy inducers or targeting mitophagy-regulating pathways would be effective in controlling autoimmune diseases.

Glycolysis in T cells is required for GVHD pathogenicity (43). T cells reduced their glycolytic activity in $\mathrm{C}_{3} \mathrm{aR}^{-/-} / \mathrm{C}_{5} \mathrm{aR}^{-/-}$recipients (Figure $6 \mathrm{~A}$ ), which correlated with GVHD outcome. The results support an important role of $\mathrm{C} 3 \mathrm{aR} / \mathrm{C} 5 \mathrm{aR}$ signaling in DCs in maintaining metabolic capacity of donor T cells after $\mathrm{HCT}$. In support of our interpretation, $\mathrm{C} 3 \mathrm{aR} / \mathrm{C} 5 \mathrm{aR}$ signaling initiated by $\mathrm{DC}$ s has been found to activate mTORC1, a central metabolic regulator critical for maintaining glycolysis in T cells (21). Additionally, in the absence of $\mathrm{C} 3 \mathrm{aR} / \mathrm{C} 5 \mathrm{aR}$, DCs decreased the expression of costimulatory ligands, which is required for increasing glucose uptake and glycolytic activity of $\mathrm{T}$ cells.

Direct engagement of $\mathrm{C} 3 \mathrm{a} / \mathrm{C} 5 \mathrm{a}$ secreted by recipient APCs with their receptors expressed on $\mathrm{T}$ cells induces their Th1/Th17 differentiation (16). We found that C3aR/C5aR deficiency skews donor T cells from Th1 differentiation toward Treg generation in GVHD target organs. Because C3aR/C5aR ligation on DCs induces the release of Th1/Th17-priming cytokines (16), we reasoned that the cytokine environment created by DCs upon $\mathrm{C} 3 \mathrm{a} / \mathrm{C} 5 \mathrm{a}$ engagement plays a fundamental role in T cell differentiation after HCT.

$\mathrm{T}$ cell migration to GVHD target organs is required for GVHD development (20). C3a/C5a are chemotactic for lymphocyte migration toward injured organs $(46,47)$. Therefore, the reduced level of $\mathrm{C} 3 \mathrm{a} / \mathrm{C} 5 \mathrm{a}$ in GVHD target organs may cause fewer donor CD4 and CD8 T cells to infiltrate into the livers of C3aR ${ }^{-1-}$ $\mathrm{C} 5 \mathrm{aR}^{-/-}$recipients. In addition, the decreased expression of CXCR3 and CCR6, gut- and live-homing chemokines, respectively, on donor $\mathrm{T}$ cells was likely caused by reduced glycolytic and $\mathrm{mTORC1}$ activities in donor $\mathrm{T}$ cells in $\mathrm{C} 3 \mathrm{aR} / \mathrm{C} \mathrm{aR}^{-/-}$recipients (48), which could have contributed to less $\mathrm{T}$ cell accumulation in GVHD target organs. However, the reduced donor $\mathrm{T}$ cell survival may also contribute to this outcome.

We observed that C3aR/C5aR deficiency in the host severely impaired GVL activity. Accumulation of immunosuppressive cells caused tumor relapse (49), the GVL impairment evidenced in $\mathrm{C}_{3} \mathrm{aR}^{-/} / \mathrm{C}^{-1} \mathrm{aR} \mathrm{R}^{-/}$ recipients may relate to the accumulation of iTregs and/or decreased donor $\mathrm{T}$ cell survival and activity. Importantly, for translational potential, we discovered that a preventative treatment with a single dose of C3aRA/C5aRA effectively preserved GVL activity. This preservation likely benefited from sparing donor T cells with C3aRA/C5aRA after transplant. Mechanistically, the CTL activity, survival, stemness, and memory formation of donor CD8 T cells were maintained after a single dose of C3aR/C5aR antagonists. $\mathrm{C} 3 \mathrm{a} / \mathrm{C} 5 \mathrm{a}$ generated from tumor (50) may also contribute to DC maturation to induce $\mathrm{T}$ cell alloreactivity and to subsequently preserving GVL activity.

In summary, this study has revealed for the first time to our knowledge that manipulation of mitophagy in recipient DCs before HCT can be an effective approach to control GVHD while maintaining GVL activity. We provide what we believe to be a novel mechanism by which complement receptors C3aR/ $\mathrm{C} 5 \mathrm{aR}$ regulate GVHD pathogenicity. Antagonists of $\mathrm{C} 3 \mathrm{aR}$ and $\mathrm{C} 5 \mathrm{aR}$ or mitophagy inducers may enable translation into new therapeutic strategies for GVHD control.

\section{Methods}

Animals and chemicals. C3aR/C5aR double-deficient mice on C57BL/6 or BALB/c backgrounds were bred and housed at the Medical University of South Carolina (MUSC). FVB (H-2q, CD45.1), C57BL/6 (H-2 ${ }^{\mathrm{b}}$, CD45.2), B6 Ly5.1 (H-2 $\left.2^{\mathrm{b}}, \mathrm{CD} 45.1\right), \mathrm{B} 6 \mathrm{D} 2 \mathrm{~F} 1\left(\mathrm{H}-2^{\mathrm{b} / \mathrm{d}}, \mathrm{CD} 45.2\right)$, and BALB/c $\left(\mathrm{H}-2^{\mathrm{d}}\right)$ mice were purchased from the National Cancer Institute or Charles River Lab. Animals were maintained in pathogen-free facilities in the American Association for Laboratory Animal Care-accredited Animal Resource Center at MUSC. The C5a receptor antagonist, the cyclic compound AcF-[OPdChaWR] (known as 3D53 or PMX53) (51), was provided in-house at University of Queensland. The C3aR antagonist, SB290157, was procured from Cayman Chem.

Cell preparation. T cells were purified from pooled spleens and lymph nodes by negative selection to remove magnetically labeled non-T cells, including B cells, NK cells, DCs, macrophages, granulocytes, and erythroid cells, as described before (43). Briefly, non-T cells were indirectly magnetically labeled by using a cocktail of biotin-conjugated antibodies against CD45R (B220) (eBioscience, clone RA3-B2), CD49b (DX5) (eBioscience, clone DX5), CD11b (Mac-1) (eBioscience, clone M1/70), and Ter-119 (eBioscience, clone Ter-119) as well as anti-biotin MicroBeads (Miltenyi Biotec). T cell-depleted BM (TCD-BM) cells were prepared from donor tibias and femurs with anti-Thy1.2 antibodies (BioXcell) and complement incubation (43). 
GVHD/GVL models. Recipient mice were lethally irradiated at 700 cGy for BALB/c and 1000-1200 cGy (2 split doses, 3-hour interval) for B6 or B6D2F1 mice using an X-RAD 320 irradiator (Precision $\mathrm{X}$-Ray). BALB/c or B6 irradiated recipient mice were transplanted with $5.0 \times 10^{6} /$ mouse BM cells from FVB or TCD-BM from B6 donors with or without T cells $\left(0.5-1 \times 10^{6} /\right.$ mouse). Recipient survival was monitored throughout the experiment. The development of GVHD was monitored twice per week for weight loss and once per week for clinical signs of posture, skin damage, hair loss, ruffled fur, diarrhea, and decreased activity. For GVL setting, the tumor cells were injected i.v. on the same day of transplantation. In case of luciferase-transduced B cell lymphoma A20 (2000 cells/mouse), tumor burden was estimated with bioluminescent imaging (BLI) (49) using a Xenogen-IVIS 200 in vivo Imaging System (Perkin-Elmer). MLL-AF9 and eGFP ${ }^{+}$Raji tumor cells were provided by Sophie Paczesny (Indiana University School of Medicine, Indianapolis, Indiana, USA) (52) and Defu Zeng (City of Hope, Duarte, California, USA) (53), respectively. For these cell lines, the tumor mass was determined via the percentages of $\mathrm{GFP}^{+}$cells in peripheral blood using flow cytometry.

Lymphocyte isolation from recipient liver. Livers were homogenized and passed through a $70-\mu \mathrm{m}$ cell strainer. Pellets were resuspended in PBS, overlaid on Ficoll (MilliporeSigma), and centrifuged at $500 \mathrm{~g}$ for 20 minutes. Lymphocytes were recovered from the interface (54).

Metabolic assays. The metabolic profile of DCs was determined using a Seahorse Extracellular Flux (XF) 96 Analyzer (Seahorse Biosciences) to measure the oxygen consumption rate (OCR), an indicator of mitochondrial respiration in real time in live cells (35). Several measures of mitochondrial respiration, including basal respiration, ATP-linked respiration, proton leak respiration, and reserve capacity, were derived by the sequential addition of pharmacological agents to the respiring cells. First, baseline cellular oxygen consumption was measured, from which basal respiration was derived by subtracting nonmitochondrial respiration. Next, oligomycin $(1.0 \mu \mathrm{M})$, an inhibitor of complex V, was added, and the resulting OCR was used to derive ATP-linked respiration (by subtracting the oligomycin rate from baseline cellular OCR) and proton leak respiration (by subtracting nonmitochondrial respiration from the oligomycin rate). Next carbonyl cyanide-p-trifluoromethoxyphenyl-hydrazone (FCCP, $1 \mu \mathrm{M})$, a protonophore, was added to collapse the inner membrane gradient, driving the ETC to function at its maximal rate. The maximal respiratory capacity was derived by subtracting nonmitochondrial respiration from the FCCP OCR. Finally, antimycin A (100 nM), a complex III inhibitor, and rotenone $(2 \mu \mathrm{M})$, a complex I inhibitor, were added to shut down ETC function, revealing nonmitochondrial respiration. The mitochondrial reserve capacity was calculated by subtracting basal respiration from maximal respiratory capacity.

BM-derived DCs. DCs were generated from the BM of 8- to 12-week-old mice. BM cells were flushed from the femurs and tibias with RPMI containing $1 \% \mathrm{FCS}, 100 \mathrm{U} / \mathrm{ml}$ of penicillin/streptomycin, and $2 \mathrm{mM} 1$-glutamine. The single-cell suspension was then filtered through a nylon mesh strainer (70 mm; BD Biosciences) and washed twice with the same medium. BM cells $\left(10 \times 10^{6} /\right.$ petri dish) were differentiated in the presence of GM-CSF (20 ng/ml, PeproTech) in complete culture medium (RPMI containing 10\% FBS, $100 \mathrm{U} / \mathrm{ml}$ of penicillin/streptomycin, $2 \mathrm{mM}$ 1-glutamine, and $50 \mathrm{mM}$ b-mercaptoethanol) for 6 days. Half of the medium was replaced every other day with an equal volume of GM-CSF, containing culture medium on the day 3 . Immature DCs were stimulated with LPS ( $25 \mu \mathrm{g} / \mathrm{ml}$, MilliporeSigma) for 20 hours.

Chromatographic analysis of sphingolipids. Lipid extractions and analyses were performed by Lipidomics Shared Resource, Analytical Unit, MUSC. Briefly, cells were lysed with a RIPA buffer (MilliporeSigma). Further preparation of samples and advanced analyses of endogenous bioactive sphingolipids were performed on the ThermoFisher TSQ Quantum liquid chromatography/triple-stage quadrupole mass spectrometer system, operating in a multiple reaction monitoring positive ionization mode, as previously described (32). Lipid levels were normalized to the cell number.

Immunofluorescence staining. BM-DCs were stained directly with LysoTracker Red (LTG, $1 \mu \mathrm{M})$ and MitoTracker Green (MTG, $1 \mu \mathrm{M}$ ) (Molecular Probes) in PBS (pH 7.4). For other staining, BM-DCs were fixed with $4 \%$ paraformaldehyde at $37^{\circ} \mathrm{C}$ for 10 minutes and permeabilized with $0.1 \%$ saponin in $\mathrm{PBS}(\mathrm{pH}$ 7.4) for 10 minutes at room temperature. The cells were then blocked with $1 \%$ BSA in PBS (pH 7.4) for 20 minutes. Cells were incubated for 18 hours at $4^{\circ} \mathrm{C}$ with primary antibodies specific for Ceramide (MID15B4, Enzo Life Sciences, 1:100) and Tom20 (Santa Cruz Biotechnology, 1:100) in blocking solution followed by Alexa Fluor 488- or Alexa Fluor 594-conjugated secondary antibodies (Jackson ImmunoResearch, 1:2000) for 1 hour. Immunofluorescence was performed using a Leica TSC SP2 AOBS TCS confocal microscope or an Olympus FV10i microscope with 543- and 488-nm channels for visualizing red and green fluorescence. 
Images were taken at $\times 25, \times 63$, or $\times 90$ magnification. At least 3 random fields were selected and images were quantified with free online software from Fiji.

Western blotting. Western blotting was performed as described previously $(11,32)$. Cell pellets $\left(1 \times 10^{6}\right)$ were washed once with ice-cold PBS, lysed in lysis buffer containing a protease inhibitor cocktail (MilliporeSigma Corp.), and processed as previously described (55). Fifty micrograms of protein per sample were separated on NuPAGE 4\%-12\% Bis-Tris gels (Invitrogen) and transferred to nitrocellulose membranes (Bio-Rad). Following transfer, membranes were blocked for 1 hour at room temperature in Tris-buffered saline containing 5\% dry milk and incubated overnight at $4^{\circ} \mathrm{C}$ or at room temperature (anti-FLIP) with LC3B antibodies (Cell Signaling, 1:2000). Following overnight incubation, membranes were washed and incubated for 1 hour at room temperature with secondary antibody. Membranes were then washed 3 times and incubated at room temperature with Super Signal HRP substrate for 5 minutes (Pierce). The blots were visualized with ECL reagents (GE Healthcare). Band densitometries were quantified using NIH ImageJ software.

Flow cytometry. The following antibodies were used for cell-surface staining: anti-CD4 (clone RM4-5, BD Biosciences), anti-CD8 (clone 53-6.7, BD Biosciences), anti-H-2 ${ }^{q}$ (KH114, Biolegend), anti-CXCR3-biotin (CXCR3-173, eBioscience), anti-CCR6-AF647 (BioLegend, clone 29-2L17), anti-FasL (MFL3, BD Biosciences), anti-PD-1 (MFL3, eBioscience), anti-NK1.1 (PK136, eBioscience), anti-CD44 (IM7, Biolegend), anti-CD62L (MEL-14, eBioscience), anti-TCR $\beta$ (H57-597, BD Biosciences), and anti-CD11b (M1/70, eBioscience). Biotinylated antibodies were detected using APCcy7 (BD Biosciences, catalog 554063) or PEcy7 (BD Biosciences, catalog 557598) conjugated to streptavidin. To measure intracellular cytokines, cells were stimulated for $4-5$ hours at $37^{\circ} \mathrm{C}$ with PMA (100 ng/ml, MilliporeSigma) and ionomycin (100 ng/ml; Calbiochem, EMD) in the presence of GolgiStop (BD Biosciences). Fix and permeabilization were performed using Cytofix/Cytoperm Plus (BD Biosciences), followed by staining with the appropriate antibodies, including anti-IFN- $\gamma$ (clone XMG1.2, eBioscience), anti-IL-17 (clone TC1118H10.1, BioLegend), anti-IL-4 (clone 11B11, BD Biosciences), anti-IL-5 (clone TRFK5, eBioscience), anti-FOXP3, (clone FJK-16s, eBioscience), anti-Ki67 (16A8, Biolegend), and anti-pS6-AF467 (Cell Signaling Technology, clone D57.2.2E). The Live/dead yellow cell staining kit (catalog L-34968) and CFSE (catalog C1157) were purchased from Invitrogen. Apoptosis was measured by Annexin V kit (BD Biosciences). Autophagy was determined by Cyto-ID dye (Autophagy detection kit, Enzo Life Science). Data were analyzed with FlowJo software (Tree Star). Blood was collected from recipients 14 days after BMT, and serum cytokines were quantified using a cytometric bead assay kit (BD Biosciences, catalog 560485).

Statistics. Data were analyzed using Prism GraphPad (version 7). Briefly, comparisons between two groups were calculated using a 2-tailed Student's $t$ test. Clinical scores and body weight loss were compared using a nonparametric Mann-Whitney $U$ test. The log-rank (Mantel-Cox) test was utilized to analyze survival data. A $P$ value less than 0.05 was considered significant.

Study approval. All animal procedures were approved by the Institutional Animal Care and Use Committee of MUSC.

\section{Author contributions}

$\mathrm{HN}, \mathrm{BO}$, and XZY participated in design of research studies. HN, SK, DB, JK, MZ, M. Dany, M. Dai, $\mathrm{JLH}, \mathrm{AD}, \mathrm{SI}, \mathrm{SS}, \mathrm{JF}$, and YW participated in conducting experiments and acquiring data. HN, M. Dany, and JK analyzed data. HN participated in interpretation of data. HN and XZY wrote manuscript. HN, SK, DB, DPF, CA, BO, ST, SGV, and XZY participated in editing of the manuscript.

\section{Acknowledgments}

We thank the Lipidomics Shared Resource Facility, Cell and Molecular Imaging Core, Flow Cytometry Core, and Pathology Core at MUSC for their valuable services. We thank Gyda and Craig Beeson (MUSC) for assistance with the Seahorse Biosciences analyzer. We thank Sophie Paczesny (Indiana University School of Medicine) and Defu Zeng (City of Hope) for providing tumor cell lines. This work is partially supported by NIH grants (R01 CA118116, R01 CA169116, R01 AI118305, and R21 CA192202 to XZY and R01 CA173687, R01 CA088932, R01 DE016572, and P01 CA203628 to BO) and the SmartState Endowment in Lipidomics and Drug Discovery to BO. Institutional resources at the MUSC were supported by NIH C06 RR15455 and P30 CA138313 grants (to the Hollings Cancer Center). DPF was supported by Australian National Health and Medical Research Council grants (1117017 and 1145372). 
Address correspondence to: Xue-Zhong Yu, Department of Microbiology and Immunology, MSC 955, Medical University of South Carolina, 86 Jonathan Lucas Street, Charleston, South Carolina 29425-5090, USA. Phone: 843.792.4756; Email: yux@musc.edu.

1. Pasquini MC, Wang Z, Horowitz MM, and Gale RP. 2010 report from the Center for International Blood and Marrow Transplant Research (CIBMTR): current uses and outcomes of hematopoietic cell transplants for blood and bone marrow disorders. Clin Transpl. 2010:87-105.

2. Stenger EO, Turnquist HR, Mapara MY, Thomson AW. Dendritic cells and regulation of graft-versus-host disease and graft-versus-leukemia activity. Blood. 2012;119(22):5088-5103.

3. Levine B, Mizushima N, Virgin HW. Autophagy in immunity and inflammation. Nature. 2011;469(7330):323-335.

4. Wang RC, Levine B. Autophagy in cellular growth control. FEBS Lett. 2010;584(7):1417-1426.

5. Le Texier L, et al. Autophagy-dependent regulatory T cells are critical for the control of graft-versus-host disease. JCI Insight 2016;1(15):e86850.

6. Hubbard-Lucey VM, et al. Autophagy gene Atg16L1 prevents lethal T cell alloreactivity mediated by dendritic cells. Immunity. 2014;41(4):579-591.

7. Cooney R, et al. NOD2 stimulation induces autophagy in dendritic cells influencing bacterial handling and antigen presentation. Nat Med. 2010;16(1):90-97.

8. Stenger EO, et al. IL-12hi rapamycin-conditioned dendritic cells mediate IFN- $\gamma$-dependent apoptosis of alloreactive CD4+ T cells in vitro and reduce lethal graft-versus-host disease. Biol Blood Marrow Transplant. 2014;20(2):192-201.

9. Lemasters JJ. Selective mitochondrial autophagy, or mitophagy, as a targeted defense against oxidative stress, mitochondrial dysfunction, and aging. Rejuvenation Res. 2005;8(1):3-5.

10. Thomas RJ, et al. HPV/E7 induces chemotherapy-mediated tumor suppression by ceramide-dependent mitophagy. EMBO Mol Med. 2017;9(8):1030-1051

11. Sentelle RD, et al. Ceramide targets autophagosomes to mitochondria and induces lethal mitophagy. Nat Chem Biol. 2012;8(10):831-838.

12. Tsoi MS, et al. Deposition of IgM and complement at the dermoepidermal junction in acute and chronic cutaneous graft-vshost disease in man. J Immunol. 1978;120(5):1485-1492.

13. Seignez A, et al. Serum Gp96 is a chaperone of complement-C3 during graft-versus-host disease. JCI Insight. 2017;2(6):e90531.

14. Ma Q, et al. Reduced graft-versus-host disease in C3-deficient mice is associated with decreased donor Th1/Th17 differentiation. Biol Blood Marrow Transplant. 2012;18(8):1174-1181.

15. Kwan WH, et al. Antigen-presenting cell-derived complement modulates graft-versus-host disease. J Clin Invest. 2012;122(6):2234-2238.

16. Raedler H, Heeger PS. Complement regulation of T-cell alloimmunity. Curr Opin Organ Transplant. 2011;16(1):54-60.

17. Strainic MG, et al. Locally produced complement fragments $\mathrm{C} 5 \mathrm{a}$ and $\mathrm{C} 3 \mathrm{a}$ provide both costimulatory and survival signals to naive CD4+ T cells. Immunity. 2008;28(3):425-435.

18. Barchet $\mathrm{W}$, et al. Complement-induced regulatory $\mathrm{T}$ cells suppress $\mathrm{T}$-cell responses but allow for dendritic-cell maturation. Blood. 2006;107(4):1497-1504

19. Blazar BR, Murphy WJ, Abedi M. Advances in graft-versus-host disease biology and therapy. Nat Rev Immunol. 2012;12(6):443-458

20. Shlomchik WD. Graft-versus-host disease. Nat Rev Immunol. 2007;7(5):340-352.

21. Hess C, Kemper C. Complement-mediated regulation of metabolism and basic cellular processes. Immunity. 2016;45(2):240-254.

22. Wang RC, et al. Akt-mediated regulation of autophagy and tumorigenesis through Beclin 1 phosphorylation. Science. 2012;338(6109):956-959.

23. Arbore G, et al. T helper 1 immunity requires complement-driven NLRP3 inflammasome activity in $\mathrm{CD} 4^{+} \mathrm{T}$ cells. Science. 2016;352(6292):aad1210.

24. Hu R, et al. Complement C5a exacerbates acute lung injury induced through autophagy-mediated alveolar macrophage apoptosis. Cell Death Dis. 2014;5:e1330.

25. Kolev M, et al. Complement regulates nutrient influx and metabolic reprogramming during Th1 cell responses. Immunity. 2015;42(6):1033-1047.

26. Bunting MD, et al. GVHD prevents NK-cell-dependent leukemia and virus-specific innate immunity. Blood. 2017;129(5):630-642.

27. Li K, et al. Functional modulation of human monocytes derived DCs by anaphylatoxins C3a and C5a. Immunobiology. 2012;217(1):65-73.

28. Ding WX, et al. Nix is critical to two distinct phases of mitophagy, reactive oxygen species-mediated autophagy induction and Parkin-ubiquitin-p62-mediated mitochondrial priming. J Biol Chem. 2010;285(36):27879-27890.

29. Guicciardi ME, Gores GJ. Life and death by death receptors. FASEB J. 2009;23(6):1625-1637.

30. Cooke KR, et al. LPS antagonism reduces graft-versus-host disease and preserves graft-versus-leukemia activity after experimental bone marrow transplantation. J Clin Invest. 2001;107(12):1581-1589.

31. Chen S, et al. MicroRNA-155-deficient dendritic cells cause less severe GVHD through reduced migration and defective inflammasome activation. Blood. 2015;126(1):103-112.

32. Dany M, et al. Targeting FLT3-ITD signaling mediates ceramide-dependent mitophagy and attenuates drug resistance in AML. Blood. 2016;128(15):1944-1958.

33. Ogretmen B. Sphingolipid metabolism in cancer signalling and therapy. Nat Rev Cancer. 2018;18(1):33-50.

34. Hill BG, et al. Integration of cellular bioenergetics with mitochondrial quality control and autophagy. Biol Chem. 2012;393(12):1485-1512.

35. Everts B, et al. Commitment to glycolysis sustains survival of NO-producing inflammatory dendritic cells. Blood. 2012;120(7):1422-1431. 
36. Pfleger J, He M, Abdellatif M. Mitochondrial complex II is a source of the reserve respiratory capacity that is regulated by metabolic sensors and promotes cell survival. Cell Death Dis. 2015;6:e1835.

37. Pan J, et al. Interferon-gamma is an autocrine mediator for dendritic cell maturation. Immunol Lett. 2004;94(1-2):141-151.

38. Shlomchik WD, et al. Prevention of graft versus host disease by inactivation of host antigen-presenting cells. Science. 1999;285(5426):412-415.

39. Koyama M, et al. Recipient nonhematopoietic antigen-presenting cells are sufficient to induce lethal acute graft-versus-host disease. Nat Med. 2011;18(1):135-142.

40. Ruiz A, et al. Effect of hydroxychloroquine and characterization of autophagy in a mouse model of endometriosis. Cell Death Dis. 2016;7:e2059.

41. Chude CI, Amaravadi RK. Targeting autophagy in cancer: update on clinical trials and novel inhibitors. Int J Mol Sci. 2017;18(6).

42. Castor MG, Pinho V, Teixeira MM. The role of chemokines in mediating graft versus host disease: opportunities for novel therapeutics. Front Pharmacol. 2012;3:23.

43. Nguyen HD, et al. Metabolic reprogramming of alloantigen-activated T cells after hematopoietic cell transplantation. J Clin Invest. 2016;126(4):1337-1352.

44. Chakraverty R, Sykes M. The role of antigen-presenting cells in triggering graft-versus-host disease and graft-versus-leukemia Blood. 2007;110(1):9-17.

45. Michonneau D, Sagoo P, Breart B, Garcia Z, Celli S, Bousso P. The PD-1 axis enforces an anatomical segregation of CTL activity that creates tumor niches after allogeneic hematopoietic stem cell transplantation. Immunity. 2016;44(1):143-154.

46. Gerard C. Inflammatory chemokines: tuned in, turned on, dropped out. Nat Immunol. 2005;6(4):366-368.

47. Nataf S, Davoust N, Ames RS, Barnum SR. Human T cells express the C5a receptor and are chemoattracted to C5a. J Immunol. 1999;162(7):4018-4023.

48. Chen W, et al. Antigen-specific immune modulation targets mTORC1 function to drive chemokine receptor-mediated $\mathrm{T}$ cell tolerance. J Immunol. 2016;197(9):3554-3565.

49. Heinrichs J, et al. CD8(+) Tregs promote GVHD prevention and overcome the impaired GVL effect mediated by CD4(+) Tregs in mice. Oncoimmunology. 2016;5(6):e1146842.

50. Afshar-Kharghan V. The role of the complement system in cancer. J Clin Invest. 2017;127(3):780-789.

51. Monk PN, Scola AM, Madala P, Fairlie DP. Function, structure and therapeutic potential of complement C5a receptors. Br J Pharmacol. 2007;152(4):429-448.

52. Ramadan A, et al. Specifically differentiated T cell subset promotes tumor immunity over fatal immunity. J Exp Med 2017;214(12):3577-3596.

53. Ni X, et al. PD-L1 interacts with CD80 to regulate graft-versus-leukemia activity of donor CD8+ T cells. J Clin Invest. 2017;127(5):1960-1977.

54. Liang Y, et al. Beta2 integrins separate graft-versus-host disease and graft-versus-leukemia effects. Blood. 2008;111(2):954-962

55. Liu X, et al. Modulation of ceramide metabolism enhances viral protein apoptin's cytotoxicity in prostate cancer. Mol Ther. 2006;14(5):637-646. 